\title{
Banking Crises and Bank Rescues: The Effect of Reputation
}

\author{
Jenny Corbett (Oxford University and CEPR) \\ Janet Mitchell (Facultes universitaires Saint-Louis (Brussels), ECARES and CEPR)
}

January 26, 2000

\begin{abstract}
This paper focuses on bank rescue packages and on the behaviour of troubled banks in light of rescue offers. A puzzling feature of experience with banking crises is that in many cases policy authorities make offers of bank rescue, and banks are reluctant to accept these offers. We study situations in which regulators have decided to offer bank rescue plans, and we show that a combination of factors, including bankers' reputational concerns, can explain banks' potential reluctance to accept offers of recapitalisation.
\end{abstract}

We would like to thank Erik Berglof, Patrick Bolton, Arnoud Boot, Aleix Calveras, Mathias Dewatripont, Xavier Freixas, Rafael Repullo, Bruce Smith, Andrew Winton, and an anonymous referee for many valuable comments. We are especially grateful to Patrick Legros for many long and helpful conversations. 


\section{Introduction}

In the 1980 s and 1990s banking sector problems, frequently escalating to crisis level, have become common. Lindgren, Garcia et al, (1996) estimated that in the decade and a half to the early 1990s over 130 countries experienced some degree of financial difficulty. Of these, thirty six countries were judged to have experienced a banking crisis. Importantly, these countries were not all developing and emerging market economies. After the Asian crisis of 1997 to 1998 several large Asian countries can now be added to the list.

Despite the frequency with which banking crises occur, relatively few formal analyses of regulatory responses to crises have been undertaken. This paper focuses on bank rescue packages and on the behaviour of troubled banks in light of rescue offers.

Much of the literature on bank regulatory policy suggests that bank rescues are inefficient and can worsen banking sector problems. The whole tenor of Prompt Corrective Action type regulation is to avoid having to bail out inadequately capitalised banks (see Bentson and Kaufman, 1997) and it may well be that this is a first-best policy response. In many cases of systemic banking crises, however, it is already too late for this type of policy response. ${ }^{1}$ Policy makers are faced with the need to recapitalise banking systems to avoid credit crunches and premature liquidations of performing projects, along with non-performing, if many banks become insolvent. This is the main reason that IMF advice frequently sanctions bank restructuring packages which involve an element of bank recapitalisation.

It is a puzzling fact, however, that in many cases policy authorities make offers of bank rescue plans, yet banks are reluctant to accept these offers. In recent years Thailand and Japan stand out as examples where government offers of recapitalisation have been received unenthusiastically by private banks. Yet the failure to get banks to recapitalise, and to restructure and write-off non-performing loans, has been one reason for poor performance in the real economy in both cases. On the other hand Norway, Sweden, and Korea provide examples where recapitalisation was achieved quite swiftly. This paper offers an explanation for these international differences that differs from potential explanations suggested by the existing literature.

\footnotetext{
${ }^{1}$ We are not suggesting that recapitalisation is a substitute for PCA and improved bank regulation. Once the short-term systemic crisis has been dealt with the usual first-best policy advice would apply.
} 
We analyse a situation in which regulators have decided to offer bank rescue plans, and show that a combination of factors, including the quality of the bank supervisory system and bankers' reputational concerns, can explain banks' potential reluctance to accept offers of recapitalisation. The analysis rests on the idea that there is asymmetric information between banks and regulators and between banks and the market regarding the amount of bad debts on banks' balance sheets. Banks may (and regularly do) hide the amount of bad debt on their balance sheets by rolling over and rescheduling loans that are in default. Banks' rollovers of defaulting loans not only disguise the banks' true financial states but also may exacerbate banking sector problems and impose costs on the real economy. In these circumstances it is less costly to have banks accept recapitalisation. ${ }^{2}$ We show, however, that there may be equilibria in which banks have incentives to reject recapitalisation and continue with loan rollovers. Banks' willingness to accept a government offer of recapitalization will depend upon the terms of the offer, but it will also depend upon the effect on banks' reputations. The reputational effect may itself be a function of whether other banks are accepting recapitalization.

This paper is related to two areas of literature. One set of papers to which the paper is indirectly related addresses the policy maker's decision on when and whether to close a bank, assuming symmetric information between banks and regulators (and all other outsiders) regarding the financial health of the bank at the point where the regulator must make the closure decision. ${ }^{3}$ (See, for example, Boot and Thakor (1993), Mailath and Mester (1994), Dreyfus, Saunders, and Allen (1994) and Rochet and Tirole (1996).) While the assumption of symmetric information is probably realistic for the case of an individual bank in difficulty, we believe it is less so in the case of widespread banking sector problems, or when a crisis is brewing. In the latter case authorities often have to decide whether or not to allow for bank rescues before undertaking detailed investigations of the potentially troubled banks in the banking system. In many recent crises the decision to create an independent financial supervisory agency with the power to investigate banks' books has been part of a package of bank restructuring policies which also included the

\footnotetext{
${ }^{2}$ Krueger and Tornell (1999) point out that a lesson from Mexican experience is that "recovery is not possible unless the banking system has been 'fixed'. If there are sizeable portions of banks' portfolios that are nonperforming, the banks themselves cannot extend new loans at reasonable rates."

${ }^{3}$ This is the theoretical literature which underpins the design of policies like PCA.
} 
offer of recapitalisation, so that detailed examination of banks could not have preceded the recapitalisation offer. ${ }^{4}$

This paper is more closely related to a second, small set of papers studying regulatory response to troubled banks in the presence of asymmetric information. (See Mitchell (1998a, 1998b), and Aghion, Bolton, and Fries (1998). $)^{5}$ These papers, like ours, focus on banks' treatment of their nonperforming loans. By establishing the incentives for banks to roll over nonperforming loans, this literature complements abundant anecdotal evidence of this practice. ${ }^{6}$ Mitchell (1998a) shows that when regulators adopt a laissez-faire policy towards troubled banks and when managers of insolvent banks would lose private benefits if the bank's insolvency were discovered, then insolvent banks will roll over their defaulting loans in order to hide their insolvency. ${ }^{7}$

An obvious policy question is whether regulators can induce accurate revelation by banks of their bad loans by offering to recapitalise banks (assuming that the bank managers who accept the recapitalisation are not dismissed). Mitchell (1998b) analyses a regulator's offer of bank rescues, and its effect on banks' revelation of nonperforming loans, when the rescue offer occurs in response to a situation labeled "too many to fail." Although insolvent banks will have the incentive to reveal their bad loans, solvent but troubled banks may roll

\footnotetext{
${ }^{4}$ In the Swedish banking crisis of the early 1990s, the Bank Support Authority was established once the authorities made the decision to allow rescues of troubled banks. Concomitantly, a procedure was devised for soliciting information regarding the amount of loan defaults on the balance sheets of any bank requesting assistance. In Japan the Financial Supervisory Agency, whose staff of bank inspectors is considerably larger than the former supervision team at the Ministry of Finance, was established late in the crisis to administer the recapitalisation program. Banks requesting assistance are required to submit detailed accounts to the Financial Reconstruction Commission which are subsequently made public. None of this account information was previously available.

${ }^{5}$ O'Hara (1993) and Rajan (1994) model banks' treatment of bad loans under the assumption of asymmetric information between insiders and outsiders; however, the contexts are quite different from this paper. Dewatripont-Tirole (1994) also assume asymmetric information between regulators and banks; however, they do not endogenize the bank's choice or analyse the regulator's bank closure decision.

${ }^{6}$ For example, Corbett (1998) provides a revealing quote from Lindgren et al.: "In addition, owners and managers of unsound banks have incentives to show loans as performing in order not to lose their bank." In an IMF discussion of "risky" assumptions that analysts often make when working with economies where there is no strong tradition of private ownership, Roulier (1997) notes, that "bank managers still function under incentives that encourage rolling over rather than collecting bad debts."

${ }^{7}$ Troubled by solvent banks may also roll over loans in Mitchell (1998b) and Rajan (1994).
} 
over their bad loans in the expectation of being rescued. Aghion, Bolton, and Fries (1998) show that if insolvent banks are recapitalised and bank managers not dismissed, solvent banks have an incentive to overstate their levels of bad debt (through excessive liquidation of loans in default) in order to qualify for recapitalization.

Yet, no paper in the literature provides a potential explanation for the problem observed in practice that too few, rather than too many, banks may come forward to accept the government's recapitalization offer. Although some anecdotal evidence suggests that some unsuccessful recapitalisation programs have failed because the conditions imposed on banks were too stringent (for example, in Thailand), other anecdotal evidence suggests that this is not the only source of reluctance to accept recapitalisations. Our proposed explanation relates to banks' reputational concerns.

Some empirical examples help to illustrate both the relevance of the question as to why banks might refuse rescue offers and the plausibility of our proposed explanation. First, in order for banks to refuse a rescue offer, they must have a choice about whether to accept the offer. This requires that recapitalisation is offered to the banks rather than imposed. In countries where banking sectors consist largely of state-owned banks, recapitalization may be more likely to be imposed upon banks, provided that regulators are fully aware of the banks' problems. Yet, even here banks may have a choice as to how much recapitalization they apply for, especially when recapitalization is linked to the restructuring of loans or to transfers of loans to a hospital bank. (This was the case, for example, in the Hungarian bank consolidation program.) In the cases of Mexico, Japan, Thailand, Malaysia, and Korea, privately-owned banks were at the core of the recapitalisation program. In Mexico, Japan and Thailand banks could voluntarily apply for programs while in Korea and Malaysia some coercion seems to have been applied (see Athukorala (1999) and Smith (1999).

A second key observation is that in several cases where banks do have a choice, they are reluctant to apply for recapitalisation. McQuerry (1999) notes that in Mexico fewer banks than expected participated in the first-round recapitalisation program offered after the 1994 currency crisis. She cites a report commissioned by the Mexican government which attributed banks' reluctance to participate to the fact that the market considered participation by banks as a sign of weakness. In Japan several offers of recapitalisation since 1995 have met with very limited take-up. Of a Japanese package offered in March, 
1998 less than $8 \%$ was taken up. Moreover, anecdotal evidence suggests that government pressure had to be applied to stronger banks to participate in order for weaker banks not to suffer reputational damage. An even more substantial package offered in early 1999 also had low take up and ultimately was accepted only when all the major banks applied together, submitting all their requests on exactly the same day. This strongly suggests that reputational effects should not be ignored. Another telling example is provided by Thailand, where only a tiny proportion of the available recapitalisation package has been used and almost all major banks have rejected government funds.

Finally, numerous country studies of banking crises note the constantly moving target of bad-loan reporting in all countries and document changing official definitions, together with variable disclosure standards, as the cause. The timing of recapitalisation offers and the subsequent revisions of estimates of bad loans in many cases (Japan is a well-documented example) suggest that regulators have incomplete information when recapitalisation is offered. $^{8}$

Our model shows that reputational concerns can have implications for the circumstances and conditions under which banks will accept recapitalisation offers. This leads to some implications about policy design. We find that even when conditions accompanying a recapitalisation program are very "soft," banks may refuse to accept the plan. In order to compensate bankers for the negative reputational effects of accepting the plan, regulators may have to offer large amounts of recapitalisation that are unrelated to the degree of the bank's insolvency. Regulators who are constrained in the amount of recapitalisation that they can offer may be unable to undertake rescues.

Bank supervisory systems help to allay the consequences of bankers' reputational concerns. Specifically, if the probability of detecting banks who reject rescue offers and attempt to hide their bad debt is high enough, the regulator can induce troubled banks to accept rescue plans (and reveal their nonperforming loans) with less recapitalisation than if the probability of detection is low. Thus, a strong bank supervisory system aids the regulator who opts for bank rescues. This result also suggests an explanation for international differences in banks' willingness to accept rescue offers.

\footnotetext{
${ }^{8}$ McQuerry (1999) also notes that although the Mexican government reacted swiftly to the crisis by proposing recapitalization and restructuring programs, "the absence of an established regulatory oversight agency made it virtually impossible for the authorities to discern the breadth of the crisis."
} 
We also derive results relating to the conditions accompanying rescue plans. Whereas the regulator must avoid punishing bankers who accept rescue plans, the regulator will want to impose costs on bankers who reject rescue plans but who later perform poorly. By imposing tough conditions on banks that reject rescue plans rather than on banks that accept plans, the regulator can induce banks to accept plans with smaller amounts of recapitalisation. A final result relating to rescue plans is that even when the regulator takes account of bankers' reputational concerns in designing a rescue plan, rejection of the plan may occur in equilibrium.

The paper proceeds as follows. Section 2 of the paper sets out the model, which bears some similarity to the model of Rajan (1994). Section 3 analyses bank responses to rescue offers for the case of a single bank. Much of the intuition of the model comes through in this section. Section 4 analyses bank responses in the model with two banks and investigates how a bank's willingness to accept a rescue plan is influenced by other banks' performance. Section 5 discusses the regulator's optimal choice of rescue plan, given banks' reputational concerns. Section 6 concludes.

\section{Model Description}

Several of the basic elements of the model resemble features of the model of Rajan (1994). We consider an economy with banks (of identical size), many potential borrowers and a public market, which could be the labour market for bank managers or the stock or bond market. $^{9}$ The probability that banks experience loan defaults is a function of the state of the world, which we take to be the severity of the banking crisis, and of the banker's type (ability). The possible states of the world are a "non-severe" crisis $n$ or a severe crisis $s$. Loan defaults may occur in either state of the world; however, the probability that a bank has loan defaults is greater when the crisis is severe than when it is non-severe. A

\footnotetext{
${ }^{9}$ There is no explicit difference made between the utility function of bank managers and owners of banks. The reputation term in the utility function can be taken to be the manager's labour market reputation or some element of utility (such as bonuses) tied to the banks' reputation (i.e. stock market value). Alternatively the utility function may be taken to refer to shareholder's utility, in which case the reputation term could be taken to be the stock market valuation itself. As will become evident below our interpretation is more appropriately applied to managers than to owners.
} 
non-severe crisis may be thought of as a situation in which problems arise in the banking sector, but the problems have not become widespread enough to be labeled a severe crisis.

Banks' abilities, or types, are denoted by $H$ (high) or $L$ (low). A bank's type determines the state-dependent probability that it will suffer loan defaults. There are three possible levels of default: no default; a medium level of default; and a high level of default. Our assumptions on default levels as a function of the state of the world and the bank's type are illustrated in the following table.

\section{Nonsevere Crisis}

High type No default

Low type Prob. $\theta$ : No default

Prob. $(1-\theta)$ : Medium default

\section{Severe Crisis}

Medium default

Prob. 0: Medium default

Prob. $(1-\theta)$ : High default

These assumptions on default imply that more banks face loan defaults in a severe crisis than in a nonsevere crisis, and low-type banks may be severely distressed in a severe crisis. In the nonsevere crisis the only bank with default is the low type, which experiences a medium level of default with probability $(1-\theta)$. In the severe crisis the only bank with a high level of default is a low type. For expositional simplicity our assumptions on loan defaults are stylized. Our results are robust to changes in these assumptions. For example, allowing for a different probability $\hat{\theta}$ that a low type has medium level of default in a severe crisis or allowing for a probability $\widetilde{\theta}$ that the high type has a high level of default in a severe crisis would not alter significantly the major results of the model; however, these changes would significantly complicate the algebra. We note in the discussion of our results differences that would occur with differing model specifications.

The bank observes both the state of the world, its type, and the loan defaults in its portfolio. ${ }^{10}$ Information on the type and the level of loan defaults is private to the bank. Information on the state of the world is also private to banks; outsiders, including the regulator, do not initally observe the state of the world although they have a prior on this variable.

Assume that all banks initially have outstanding: loans with face value $B$ and liabilities of $L$. Our assumptions on default translate into balance sheet values in the following way.

\footnotetext{
${ }^{10}$ We assume, like Rajan, that each individual bank has a portfolio that is diversified enough to be able to discern the severity of the crisis by observing the defaults in its own portfolio.
} 
If a bank has a loan in the amount of $B$ in its portfolio and has no default, then it has a current net worth (or current balance sheet value) of $B-L$. We will refer to this level of current net worth as "high." When the bank has a medium level of default, its current net worth is $\widehat{B}-L$, where $0<\widehat{B}<B$. When the bank has a high level of default, its current net worth is $-L$.

The banker with defaulting loans may choose either to reveal the default (for example, by invoking bankruptcy procedures against the defaulters or writing off the loan) or to hide the default (by rolling over or refinancing the defaulting loan). If the bank "succeeds" in hiding the default, it is able to report high current net worth $(B-L)$, which is the same level of net worth as it would have reported if the borrower had not been in default. On the other hand, if the bank's attempt to hide default "fails," the bank must write off the loan and report the current net worth stated above. ${ }^{11}$

Assumption 1: When a bank with default attempts to hide its defaulting loans, it will "succeed" with probability $a$ and "fail" with probability $(1-a)$.

We interpret the variable $(1-a)$ to be the probability that the bank's attempt to hide loan defaults is detected by prudential supervisors. ${ }^{12}$ This variable is a measure of the "effectiveness" of bank supervision. Since the value of a plays a critical role in the equilibrium conditions in our model, this variable allows for comparison of the results across economies with differing qualities of supervisory institutions. It also introduces possible explanations for observed international differences in banks' acceptance of rescue plans.

We assume that when a bank with a medium level of default attempts rollover of

\footnotetext{
${ }^{11}$ We employ the term "current net worth" rather than current earnings because what is ultimately important in banking crises is the bank's balance sheet, rather than its income statement. As will be seen below, bank recapitalisation offered through a rescue plan improves the bank's balance sheet and also enters positively in the banker's utility function.

${ }^{12}$ In addition to the motivation of hiding loan defaults, banks may roll over or refinance bad loans in an attempt to gamble for resurrection. Success in the latter would imply that by waiting, the bank has succeeded in being repaid enough on its defaulting loans to avoid insolvency. In principle, the probability of success in gambling for resurrection should be different from the probability of bank supervisors detecting the rolling over of loans. We abstract in this paper from the probability of success in gambling for resurrection and focus on the latter probability. Nevertheless, in a manner consistent with models of gambling for resurrection, we assume that rolling over defaulting loans results in a lower expected future net worth for the bank.
} 
defaulting loans, it will succeed with positive probability $a$. In contrast, we assume that a bank with a high level of default is already so insolvent that even if it attempts to hide its bad loans it will become illiquid and its financial distress will be discovered in the current period; therefore, rollover will fail with certainty. The following assumption reflects these ideas.

Assumption 2: $a>0$ for banks with a medium level of default; $a=0$ for banks with a high level of default.

Although a bank that rolls over or refinances defaulting loans may succeed in hiding the default in the current period, the attempt to hide default is assumed to lower expected future recovery on the loans relative to the amount that would have been obtained if the loans had been immediately revealed and dealt with. The lower expected future loan recovery translates into lower bank net worth in the future period relative to the case where loan defaults were immediately confronted. For example, postponing liquidation of the defaulting borrower can result in a lower liquidation value since the borrower has more time to dissipate the firm's assets. Thus, even if the bank has rolled over the loan and succeeded in reporting high net worth in the current period (i.e. it's deception was not detected), the bank bears a cost $c_{b}$ next period through lower expected future net worth, where the subscript $b$ indicates that the cost is a direct cost for the bank.

Yet, despite the reduction in the bank's future net worth caused by loan rollovers, the banker may still decide to hide loan defaults because of his current private reputational concerns. The banker's reputation is defined to be proportional to the market's belief about the bank's type. The market updates its prior regarding the bank's type after observing the bank's current net worth. Thus, if the banker's expected gain in reputational benefits from hiding default (and succeeding in reporting high current net worth) exceeds the future costs generated by loan roll overs, then the banker will hide defaulting loans.

We now introduce into the model a bank regulator, who offers (or not) to rescue and recapitalise banks on the basis of her prior about the state of the world. We define a rescue plan to be an offer by the regulator to banks (that can show evidence of loan defaults) of some level of recapitalisation, possibly with some other conditions imposed. Because information on loan defaults and the state of the world is private to banks, the regulator knows neither the state of the world nor the true state of banks' balance sheets when she 
decides whether to offer a rescue package. Banks' responses to the rescue offer, together with the realization of their current net worths, will convey information about the state of the world and about each bank's financial distress. The feature of banking crises that we are intending to capture with this assumption is the observation discussed above that regulators often make the decision to allow bank rescues once a banking crisis is perceived to be severe enough; however, because of problems of asymmetric information the decision to allow for bank rescues often occurs before regulators know the exact level of default on individual banks' balance sheets and even before they know which banks will ultimately need to be recapitalised. ${ }^{13}$

A banker's acceptance of a rescue offer automatically reveals the bank's defaulting loans. ${ }^{14}$ In order for a bank to hide its loan defaults, it must reject the regulator's rescue offer. Yet, in certain circumstances the regulator (as well as other outsiders) is able to detect that a bank has attempted to hide its loan defaults. This occurs when the bank rejects the regulator's rescue offer, rolls over defaulting loans, but rollover "fails." The regulator may in this case impose an additional cost $c_{p}$ on the bank, where the subscript $p$ indicates the possiblity that this cost is a private cost for the banker. For example, the cost $c_{p}$ may represent a direct cost imposed by the regulator on "deceitful" banks (e.g. fines) or it may represent the loss of private benefits to bankers who lose control (e.g. through nationalisations) or to bankers who lose their jobs or are more heavily monitored in the future. The maximum level of the cost $c_{p}$ can be expected to vary across countries and is related, in part, to powers given to regulators in dealing with troubled banks. For example,

\footnotetext{
${ }^{13}$ The assumption that the regulator does not know the severity of the crisis is not critical to our results, although it does simplify the model by allowing us to abstract from any learning by the market of the severity of the crisis from the amount of recapitalization offered by the regulator to banks. What is important is that the regulator does not know which banks are distressed. It is possible to show that even when the regulator knows the state of the world (but not the financial situation of any given bank) the amount of recapitalization offered in equilibrium will be the same across states of the world.

The extent to which in practice the regulator or the market has more information regarding banks' financial states has been an issue of debate in the literature. Empirical studies have yielded conflicting answers to this question.

${ }^{14} \mathrm{It}$ is possible (and even suggested by Japanese experience) that banks may choose to reveal only a portion of their loan defaults when accepting an offer of recapitalization. For simplicity, we consider in this paper only the case where banks' acceptance of a rescue offer reveals the total amount of default.
} 
U.S. regulators have the power to bar bankers from the sector for life. ${ }^{15}$ This implies that $c_{p}$ is very high for the U.S. In other countries where regulators have less power and/or bankers have strong connections to the government, $c_{p}$ may be close to zero. ${ }^{16}$

Consider the situation in which a bank has defaulting loans and the regulator has made a rescue offer. If the banks wishes to reveal its loan defaults, it will accept the rescue offer. On the other hand, if the bank wishes to hide its defaults, it must reject the rescue offer. Thus, the bank's possible actions may be described as $\{\operatorname{Re}, A\}$, where Re denotes "reject" and $A$ denotes "accept" and where reject is synonymous with hiding default and accept is synonymous with revealing.

What information does the market have? When it observes "reject" and $B$, it does not know whether the bank is a high type and the state is $n$; whether the bank is a low type, the state is $n$, and rollover succeeded; or whether the bank is a high type, the state is $s$, and the bank had no default or rollover succeeded. When the market observes "accept" and $\widehat{B}$, then it knows that the bank has a medium level of default and has not rolled over its loans. However, the market does not know whether the the bank is a low type in state $n$ or state $s$, or whether the bank is a high type in state $s$. When the market observes accept and 0 , it knows that the bank is a low type and that the state is $s$.

The timing of events is as follows.

\section{Period 0}

Banks make a loan

\section{Period 1}

State of the world realized and loan defaults occur

Regulator offers rescue plan

Banks accept or reject the plan

If bank with default rejects plan, current net worth is high with probability $a$

Report of current net worth realized and observed by market

Market updates bank's reputation

\section{Period 2}

Future loan repayments and costs $\left(c_{b}\right.$ and $\left.c_{p}\right)$ realized

\footnotetext{
${ }^{15}$ We thank Alton Gilbert for pointing this out to us.

${ }^{16}$ Some observers have expressed the opinion that Thailand may fall into the latter category.
} 
In period 0 the bank makes a loan. In period 1 banks observe the state of the world, and each bank observes its level of defaulting loans. The regulator then makes a rescue offer (or not). Since the regulator does not observe the state of the world, his rescue offer conveys no information to the market about the state of the world. Banks then announce whether they accept or reject the rescue plan. If a bank with default rejects the plan, it will "succeed" with rollover with probabiliby a. After success or failure of rollover has been realized, the bank's reported current net worth is observed. The market then updates the bank's reputation. In period 2 the bank's future net worth (reflecting the ultimate repayment of defaulting loans) and costs associated with hiding default are realized.

\section{Notation and additional assumptions:}

(1) $\pi$ is the market's (and the regulator's) initial prior regarding the probability that the crisis is severe.

(2) $p$ is the market's initial prior regarding the probability that a bank is a high type.

(3) The market updates $p$ via Bayesian updating (when possible). The posterior in the case of high current net $(B-L)$ worth is labelled $p^{+}$; the posterior with medium current net worth $(\widehat{B}-L)$ is $p^{m}$; the posterior with low current net worth $(-L)$ is $p^{0}$.

(4) $R$ is the amount of recapitalization offered in a bank rescue plan.

(5) $E c=c_{b}+(1-a) c_{p}$ represent the expected costs of rolling over loans.

\subsection{The banker's objective function:}

Bank managers have an objective function which is a weighted sum of the bank's expected net worth and a term containing the bank's reputation. The general form of the banker's expected utility is given by

$$
U=(1-\gamma) \cdot(\exp . \text { net worth })+\gamma \cdot E p
$$

where $\gamma<1$ is the weight placed on reputation, and Ep represents the banker's expected reputation. For simplicity, we assume no discounting. The term expected net worth is defined to be the expected future net worth of the bank, including any recapitalisation offered by the regulator through a rescue plan, and where future net worth reflects any 
costs associated with hiding default. Expected future bank net worth for each of the differing possible cases is:

Bank with no default: $B-L$

Bank with medium level of default which accepts rescue plan: $\widehat{B}+R-L$

Bank with medium level of default which rejects rescue plan: $\widehat{B}-E c-L$

Bank with high level of default which accepts rescue plan: $R-L$

Bank with high level of default which rejects rescue plan: $-L-c_{b}-c_{p}$

Three features of these cases are worth noting. First, the bank with a medium level of default has a future expected net worth of $\widehat{B}$ if it accepts a plan (reveals its default), and therefore takes an action such as using a bankruptcy proceeding against its defaulters. This bank has a future expected net worth of something less than $\widehat{B}$ if it rejects the plan and attempts to hide its default. The fact that the cost $c_{b}$ is positive implies that hiding default is inefficient. Second, the bank with a medium level of default may be either solvent or insolvent but still liquid. We assume that if a bank with a medium level of default is insolvent, it is able to remain liquid for at least the current period. It is in fact a common feature of banking that banks may actually become insolvent long before they are illiquid. ${ }^{17}$ Finally, because a bank with a high level of default which rejects a rescue plan is discovered with certainty (Assumption 2), its expected cost of rollover is greater than that for the bank with a medium level of default which rejects the plan. The expected cost of rollover for the former bank is $c_{b}+c_{p}$, whereas for the latter this cost is $E c=c_{b}+(1-a) c_{p}$.

It is worth commenting on the implicit assumption that whereas the banker who successfully rolls over bad loans enjoys a reputational benefit in period 1 , the banker suffers no reputational cost in period 2 when its ultimate net worth turns out to be less than $B-L .^{18}$ This assumption is made, as in Rajan, in order to capture the notion that bankers' shortterm reputational concerns can affect their behavior in response to defaulting loans, despite the long-term costs of this behavior. It would be straightforward to modify the assumptions to explicitly guarantee that banks which succeed with rollover in period 1 cannot

\footnotetext{
${ }^{17}$ For example, many of the failed Savings and Loans in the U.S. Savings and Loans crisis were liquid up until the date on which they were closed.

${ }^{18}$ Note that bankers still suffer the cost $c_{b}$ in period 2, which can be defined to include costs of maintaining deposits once depositors have discovered that the bank had defaulting loans. We discuss depositor behavior in Section 6.
} 
be separated in period 2 from banks that had no defaulting loans on their balance sheets in period 1. One such assumption could be that the market does not observe the bank's period-2 net worth until period 3. If bankers either heavily discount period 3 or leave the bank at the end of period 2, no additional reputational costs will enter the banker's utility function.

Our analysis proceeds by backward induction. In Sections 3 and 4 we characterize the effects of differing rescue plans on bank behavior. In this part of the analysis we take the terms of rescue plans (i.e., the amount of recapitalisation offered and the cost $c_{p}$ ) to be exogenous, and we identify necessary and sufficient conditions for rescue plans to succeed; that is, to be accepted by banks with default on their balance sheets. In order to illustrate the basic intuition, we present in the next section a model with only one bank.

\section{The model with one bank}

Our analysis focuses on pure-strategy equilibria. We derive the equilibrium conditions for the bank's choice of strategy in the face of the regulator's offer of recapitalisation and the market's updating of the bank's reputation. The method consists of examining the bank's incentive compatibility constraints with differing combinations of strategies and identifying the range of parameter values for which the incentive compatibility conditions are satisfied.

We first note a feature that is common to all equilibria.

Lemma 1 The bank with a high level of default will always accept a rescue plan.

Proof: See appendix.

The above lemma implies that in every equilibrium the low-type bank with a high level of default in a severe crisis will accept a rescue plan. In addition, the high-type bank will always reject the plan in the nonsevere crisis, since it has no loan defaults. Every equilibrium will thus involve rejection of the plan by the high type in a nonsevere crisis and acceptance of the plan by the low type with high default in a severe crisis. Equilibria must therefore be distinguished by the action taken by the low-type bank with default in the nonsevere crisis and by the bank with medium default in the severe crisis.

We define an equilibrium in the one-bank model by a set of strategies $\left(\sigma_{n}, \sigma_{s}\right)$, where $\sigma \in\{A, \operatorname{Re}\}$ and $\sigma_{n}$ refers to the strategy that the low-type bank chooses when it has 
default in the nonsevere crisis, and $\sigma_{s}$ refers to the strategy that the bank with a medium level of default chooses in the severe crisis. (It is straightforward to verify that low-type banks with medium default in a severe crisis choose the same strategy in equilibrium as high-type banks with medium default.)

One question that we address is whether the equilibrium strategies $\sigma_{n}$ and $\sigma_{s}$ can differ. We first consider equilibria of the form $(\operatorname{Re}, \operatorname{Re})$ and $(A, A)$. We link existence of these equilibria to the strength of banking supervision, the costs of rollover, and the level of recapitalisation offered by the regulator. We then show that the equilibrium $(\operatorname{Re}, A)$ does not exist and $(A, \mathrm{Re})$ exists only for a limited range of parameter values. Finally, we characterize the pure-strategy equilibria in the one-bank model.

\subsection{Equilibrium (Re,Re)}

Suppose that the nonsevere crisis occurs. (Recall that the severity of the crisis is unobservable by the market.) The only bank that can have default in the nonsevere crisis is the low type. The expected utility for the bank with default if it rejects the plan is

$$
\begin{aligned}
U(\operatorname{Re} \mid(\operatorname{Re}, \operatorname{Re}))= & (1-\gamma) \cdot(\widehat{B}-L-E c) \\
& +\gamma\left[a p^{+}(\operatorname{Re} \mid(\operatorname{Re}, \operatorname{Re}), \pi)+(1-a) p^{m}(\operatorname{Re} \mid(\operatorname{Re}, \operatorname{Re}), \pi)\right]
\end{aligned}
$$

where $p^{+}(\operatorname{Re} \mid(\operatorname{Re}, \operatorname{Re}), \pi)$ represents the bank's updated reputation when it rejects the plan and succeeds in reporting high current net worth, given that the market expects banks with default in each state of the world to reject the plan. The term $p^{m}(\operatorname{Re} \mid(\operatorname{Re}, \operatorname{Re}), \pi)$ represents the bank's reputation when it rejects the plan, rollover fails, and it must report a current net worth consistent with a medium level of default. The values of the reputation terms are given in the appendix.

The bank's expected utility if it accepts the plan is

$$
U(A \mid(\operatorname{Re}, \operatorname{Re}))=(1-\gamma)(R+\widehat{B}-L)+\gamma p^{m}(A \mid(\operatorname{Re}, \operatorname{Re}), \pi)
$$

The market cannot calculate $p^{m}(A \mid(\operatorname{Re}, \mathrm{Re}), \pi)$ by Bayes' rule, since a bank's acceptance of a rescue plan is off the equilibrium path. We must specify the market's out-of-equilibrium belief in this case. We assume that the market assigns a value to $p^{m}(A \mid(\operatorname{Re}, \operatorname{Re}), \pi)$ by calculating the probability that the bank is a high type given that it has accepted the 
plan. ${ }^{19}$ This gives

$$
p^{m}(A \mid(\operatorname{Re}, \operatorname{Re}), \pi)=\frac{p \pi}{p \pi+(1-p)[(1-\pi)(1-\theta)+\pi \theta]}
$$

which is equal to $p^{m}(\operatorname{Re} \mid(\operatorname{Re}, \operatorname{Re}), \pi)$.

The incentive compatibility constraint for the bank with default in the non-severe crisis is given by

$$
E c+R \leq \frac{\gamma}{(1-\gamma)} a\left[p^{+}(\operatorname{Re} \mid(\operatorname{Re}, \operatorname{Re}), \pi)-p^{m}(\operatorname{Re} \mid(\operatorname{Re}, \operatorname{Re}), \pi)\right] .
$$

Now suppose that the crisis is severe. The expected utility of the bank with medium default if it rejects the plan is given by

$$
\begin{aligned}
U(\operatorname{Re} \mid(\operatorname{Re}, \operatorname{Re}))= & (1-\gamma)(\widehat{B}-L-E c) \\
& +\gamma\left[a p^{+}(\operatorname{Re} \mid(\operatorname{Re}, \operatorname{Re}), \pi)+(1-a) p^{m}(\operatorname{Re} \mid(\operatorname{Re}, \operatorname{Re}), \pi)\right],
\end{aligned}
$$

where $p^{+}(\operatorname{Re} \mid(\operatorname{Re}, \operatorname{Re}), \pi)$ and $p^{m}(\operatorname{Re} \mid(\operatorname{Re}, \operatorname{Re}), \pi)$ are defined as above. This expected utility is identical to that of the low-type bank with default in the nonsevere crisis. Similarly, the bank's expected utility if it accepts the plan is identical to the analogous utility for the low type with default in the nonsevere crisis. Thus, the incentive compatibility constraints of banks with medium default in each state of the world are identical.

Consider the IC constraint (2). This constraint implies that if the costs due to rollover are low enough and if the amount of recapitalization offered is low enough, the bank will reject the plan. It is clear that a necessary condition for this constraint to be satisfied is that the RHS is positive. The assumptions of the model guarantee that $p^{+}(\operatorname{Re} \mid(\operatorname{Re}, \operatorname{Re}), \pi) \geq$ $p^{m}(\operatorname{Re} \mid(\operatorname{Re}, \operatorname{Re}), \pi)$, with strict inequality for all $\pi<1$; thus the RHS is strictly positive for all $\pi<1$. Define the following critical value, equal to the RHS of the above IC constraint.

$$
c^{r e}(a) \equiv \frac{\gamma}{(1-\gamma)} a\left[p^{+}(\operatorname{Re} \mid(\operatorname{Re}, \operatorname{Re}), \pi)-p^{m}(\operatorname{Re} \mid(\operatorname{Re}, \operatorname{Re}), \pi)\right] .
$$

A necessary condition for the equilibrium ( $\operatorname{Re}, \operatorname{Re})$ to exist is that $E c+R \leq c^{r e}(a)$. It is straightforward to verify that $c^{r e}(a)$ is increasing in $a$. Thus, the higher is the probability of success with rollover or, equivalently, the weaker is bank supervision, the larger the range of values $E c+R$ for which the equilibrium $(\operatorname{Re}, \operatorname{Re})$ will exist.

\footnotetext{
${ }^{19}$ We have shown in an earlier version of this paper that a more extreme assumption on out-of-equilibrium beliefs, such as the assumption that $p^{m}(A \mid(\operatorname{Re}, \operatorname{Re}), \pi)=0$, further strengthens the results of this section.
} 


\subsection{Equilibrium $(\mathrm{A}, \mathrm{A})$}

As in the case of the ( $R e, R e)$ equilibrium, the incentive compatibility constraints are identical for the bank with default in the nonsevere crisis and the bank with default in the severe crisis. The expected utility for a bank with default if it accepts the plan is given by

$$
\left.U(A \mid A, A))=(1-\gamma)(R+\widehat{B}-L)+\gamma p^{m}(A \mid A, A), \pi\right)
$$

where the value of $p^{m}(A \mid(A, A), \pi)$ is given in the appendix. If the bank rejects the plan, its expected utility is

$$
U(\operatorname{Re} \mid(A, A))=(1-\gamma)(\widehat{B}-L-E c)+\gamma\left[a p^{+}(\operatorname{Re} \mid(A, A), 0)+(1-a) p^{m}(\operatorname{Re} \mid(A, A), \pi)\right]
$$

When the bank rejects the plan and reports high current net worth, the market believes that the state is $n$ and sets $\pi=0$ in updating the bank's reputation. On the other hand, $p^{m}(\operatorname{Re} \mid(A, A), \pi)$ cannot be computed via Bayes' rule, since rejecting the plan and having current net worth consistent with a medium level of default is off the equilibrium path. We assume, in a manner analogous to Section 3.1, that the market assigns a value to $p^{m}(\operatorname{Re} \mid(A, A), \pi)$ by computing the probability that the bank is a high type given that it rejects the plan and has a medium level of default. The values of the reputation terms are given in the appendix. It is easily verified that $p^{m}(\operatorname{Re} \mid(A, A), \pi)=p^{m}(A \mid(A, A), \pi)$.

The bank's IC constraint is given by

$$
E c+R \geq \frac{\gamma}{(1-\gamma)} a\left[p^{+}(\operatorname{Re} \mid(A, A), 0)-p^{m}(A \mid(A, A), \pi)\right]
$$

This constraint states that banks with default will accept the plan if the sum of the expected costs of rollover and recapitalisation are high enough. Define the following critical value, equal to the RHS of the above constraint.

$$
c^{A}(a)=\frac{\gamma}{(1-\gamma)} a\left[p^{+}(\operatorname{Re} \mid(A, A), 0)-p^{m}(A \mid(A, A), \pi)\right]
$$

A necessary condition for the equilibrium $(A, A)$ to exist is that $E c+R \geq c^{A}(a)$. It is easily verified that $c^{A}(a)$ is increasing in $a$. 


\subsection{Characterization of equilibria in the one-bank model.}

We characterize here the pure strategy equilibria in the one-bank model. The following proposition describes equilibria with state-independent strategies for banks with medium default.

Proposition 1 (i) For every a, there exist values $c^{\mathrm{Re}}(a)$ and $c^{A}(a)$, with $c^{A}(a)>c^{\mathrm{Re}}(a)$, such that an equilibrium $(A, A)$ exists if $E c+R \geq c^{A}(a)$ and an equilibrium $(\operatorname{Re}, \operatorname{Re})$ exists if $E c+R \leq c^{\mathrm{Re}}(a)$; (ii) as a increases, the equilibrium $(A, A)$ becomes less likely and the equilibrium ( $\mathrm{Re}, \mathrm{Re})$ becomes more likely.

Proof: See appendix.

Part (i) of the above proposition summarizes the discussion of the previous sections, which pertain to pure-strategy equilibria. For values of $E c+R \in\left(c^{\operatorname{Re}}(a), c^{A}(a)\right)$ equilibria are in mixed strategies. Part (ii) of the proposition illustrates the link between the strength of banking supervision and the willingness of banks to accept rescue plans. The weaker is banking supervision (i.e., the higher is $a$ ), the greater the region of the parameter space for which banks will reject rescue plans and the smaller the region for which banks will accept rescue plans. This being said, the level of recapitalisation offered by the regulator can also play an influential role in inducing acceptance of a rescue plan. More precisely, we may state the following corollaries.

Corollary 1 Let $R^{A}(a)=c^{A}(a)-$ Ec. The equilibrium $(A, A)$ exists for all $R \geq R^{A}(a)$.

Corollary $2 R^{A}(a)$ is increasing in a.

These corollaries indicate that for every value of $a$ there is a minimum level of recapitalisation $R^{A}(a)$ such that the regulator can always induce banks to accept the rescue plan by offering a level of recapitalisation that is at least as large as $R^{A}(a)$. Thus, a regulator who is unconstrained in the amount of recapitalisation offered to banks can always induce banks to accept a rescue plan and reveal their default. Corollary 2 states that the minimum recapitalisation $R^{A}(a)$ necessary to induce acceptance of rescue plans is increasing in $a$. The weaker the level of banking supervision, the greater the amount of recapitalisation that is necessary to induce banks to accept a rescue plan. 
The above corollaries illustrate how recapitalisation can compensate banks for the negative reputational effect of revealing default and induce them to accept a plan. Interestingly, the expression for $R^{A}(a)$ implies that the amount of recapitalisation required to generate an equilibrium $(A, A)$ is unrelated to the amount necessary to bring an insolvent bank to solvency. This is due to the assumption that banks with medium default can remain liquid in period 1 even though they may be insolvent, which allows banks to reject a rescue plan without fear of bank closure if they succeed in hiding their default. Bankers' reputational concerns may force the regulator to offer an amount of recapitalisation that is well above the amount necessary to restore solvency to the bank.

We now address the possibility of existence of equilibria where the strategies chosen by banks with medium default differ across the states of the world.

Proposition 2 (i) Equilibria of the form (Re,A) do not exist; (ii) Equilibria of the form $(A, R e)$ exist for a restricted range of parameter values.

Proof: See appendix.

The above proposition states that it is impossible to have an equilibrium where banks with default reject the plan in the nonsevere crisis and accept the plan in a severe crisis. In contrast, it is possible for a limited range of pairs $(E c, R)$ to have an equilibrium where banks accept the plan in a nonsevere crisis and reject in the severe crisis. This equilibrium exists only for a range of values of $E c$. Moreover, for each value of $E c$ in this range, there is only one value of $R$ for which the equilibrium can exist. Finally, the necessary and sufficient condition for existence of this equilibrium is $E c+R=\frac{\gamma}{(1-\gamma)}\left[\frac{p}{p+(1-p) \theta}\right]$, which is greater than $c^{A}(a)$. In order for this equilibrium to exist, the sum $E c+R$ must exceed the value necessary for existence of the $(A, A)$ equilibrium. Thus, for parameter values for which the equilibrium $(A, \operatorname{Re})$ exists, the equilibrium $(A, A)$ also exists.

It is worth pointing out that equilibria derived in this and the next section are actually continuation equilibria; that is, they are equilibria given some choice of $c_{p}$ and $R$ by the regulator. We show in the proposition below that the amount of recapitalization required for existence of the equilibrium $(A, \mathrm{Re})$ exceeds the minimum amount of recapitalization necessary to induce an equilibrium $(A, A)$. This result is shown in Section 5 to imply that the continuation equilibrium $(A, \mathrm{Re})$ cannot be an equilibrium when we allow for the regulator's choice of $R$ and $c_{p}$. 
Proposition 3 Suppse that $E c<\frac{\gamma}{(1-\gamma)}\left[\frac{p}{p+(1-p) \theta}\right]$. Define $\widehat{R}(a)=\frac{\gamma}{(1-\gamma)}\left[\frac{p}{p+(1-p) \theta}\right]-E c$. Then, $\widehat{R}(a)>R^{A}(a)$.

Proof: Straightforward.

The above proposition implies that the regulator can induce banks with medium default to accept the plan with a lower level of recapitalization than that required for existence of an equilibrium $(A, \operatorname{Re})$. Since we show in Section 5 that the regulator always prefers the lower level of recapitalization, we ignore the equilibrium $(A, \operatorname{Re})$ in the remaining discussion.

The results of this section suggest some possible explanations for international differences in bank behavior in banking crises. Given our interpretation of $(1-a)$ as the probability that prudential monitoring will detect the existence of rollover of defaulting loans in banks' portfolios (thus rollover will "fail"), our results suggest that in banking systems where prudential regulation is strong (i.e., $a$ is low), regulators can induce troubled banks to reveal their default by offering a rescue package with less government financial support than would be necessary if prudential regulation were weak. In contrast, in banking systems with less well developed prudential regulation, regulators are disadvantaged by banks' reputational concerns. Regulators may be required to offer large amounts of recapitalisation in order to induce banks to accept rescue offers and to reveal the default on their balance sheets. This suggests the possibility that a vicious circle can arise: weak banking supervision increases the probability of occurrence of a banking crisis; once a banking crisis develops, banks may be unwilling to reveal their bad loans unless offered a large amount of recapitalisation. Yet, regulators in countries with insufficiently strong supervisory institutions who also face constraints on the amount of recapitalisation that can be paid to banks may be unable to induce troubled banks to accept rescue plans.

Another parameter that can be linked to international differences in financial systems and regulation, and therefore, to differences in banks' reactions to rescue offers, is $c_{p}$, the cost that the regulator may impose on the banker who rejects the plan then reports low current net worth. If $c_{p}$ is high enough, the incentive compatibility constraint for the equilibrium $(A, A)$ can be satisfied, and the regulator can induce the bank to accept a plan with only negligible recapitalisation. Strikingly, this result implies not only that the regulator must refrain from imposing punishment on bankers who accept rescue plans (as pointed out by Aghion, Bolton, and Fries (1998)) but also that the regulator may want 
to impose punishment on bankers who reject rescue plans then exhibit poor performance. We show in Section 5 that any rescue plan chosen by the regulator will always impose the maximum level of $c_{p}$. As far as we are aware, the potential importance of applying punishment to banks who do not accept rescue offers and then perform poorly has not been recognized in analyses of policy responses to banking crises.

Our results relating to equilibria in the one-bank model resemble those that can be obtained in the absence of a rescue plan (see Rajan). Nevertheless, two differences stand out. First, the bank's response to the regulator's rescue offer conveys information to outsiders concerning the bank's strategy with respect to its bad loans. This information, in addition to the bank's current net worth, can be used by the market to update its prior on the severity of the crisis, which is then used in updating the bank's reputation. In the absence of a rescue offer outsiders observe only the bank's current net worth; therefore, they obtain no direct information regarding the bank's strategy. Second, the regulator who offers a rescue plan can impose the cost $c_{p}$ on a banker that rejects the plan then reports low current net worth. This cost, which does not exist in the model in which the regulator is absent, increases the probability of the bank's revealing its defaulting loans. These features lead to the result that the mere offer of a rescue plan, even one with very little recapitalisation, motivates banks to reveal their default more often (i.e., for a larger range of parameter values) than when no rescue plan is offered.

\section{Two-bank model}

We consider in this section a model with two banks, which permits us to study the interaction of banks' strategies. In this model banks' strategies become interdependent due to the fact that the market takes into account Bank 2's accept/reject decision and current performance when updating its belief about Bank 1's type, given the latter's accept/reject decision and current performance. Implicitly, the market uses Bank 2's performance to update its prior on the state of the world and then applies the updated prior on the state when it updates Bank 1's reputation. The market similarly takes into account Bank 1's performance when updating its belief about Bank 2's type. Thus, when a bank is deciding whether to accept or reject a plan, it must take into account the other bank's expected 
behavior and performance given the state of the world and the effects of this performance on the market's updating of the original bank's reputation.

As in the previous section, one of the questions of interest is whether the equilibrium strategy chosen by a bank with default in a nonsevere crisis can differ from the strategy chosen by a bank with default in a severe crisis. It is indeed reasonable to suspect that in the two-bank model the strategies chosen by banks in each state may differ. A natural conjecture, that is also suggested by the two-bank model of Rajan, is that banks with default might be more willing to reveal their bad loans in a severe crisis than in a nonsevere crisis. Since other banks are more likely to have default in a severe crisis, the market will revise upward its prior on the severe crisis; therefore, the reputational effects of revealing loan defaults will be less unfavorable. We do find that an equilibrium exists whereby banks with default accept the plan in a severe crisis whereas banks with default reject the plan when the crisis is nonsevere.

The timing of the two-bank model is as follows.

Timing

\section{Period 0}

Banks make a loan

\section{Period 1}

State of the world realized and loan defaults occur

Regulator offers rescue plan

Banks simultaneously announce acceptance or rejection of the plan

If a bank with default rejects the plan, its current net worth is high with probability $a$ Current net worth realized by both banks and observed by market

Market updates both banks' reputations

\section{Period 2}

Future loan repayments and costs $\left(c_{b}\right.$ and $\left.c_{p}\right)$ realized

As before, we focus on equilibria in pure strategies. We consider equilibria that are symmetric in Bank 1 and Bank 2's strategies; i.e., equilibria in which Bank 1 will adopt the same strategy if it is a high type as will Bank 2 if it is a high type. In order to simplify the algebra, we make two minor changes of assumption. First, we set $\gamma=1 / 2$, so that terms involving $\gamma$ drop out of the incentive compatibility conditions. Second, we assume that in 
a severe crisis low-type banks have a high level of default with certainty. Our assumptions on default are illustrated in the following table.

\section{Nonsevere Crisis}

\section{High type No default}

Low type Prob. 0: No default

Prob. $(1-\theta)$ : Medium default

\section{Severe Crisis}

Medium default

High default

Each of these changes is made for expositional purposes only. The change in our assumptions on default greatly simplifies the expressions for the reputation terms and the proofs of our results. All of our results nevertheless hold for the default assumptions analyzed in Section $3 .^{20}$

As in the previous section all equilibria in the two-bank model have the characteristic that banks with high default accept the plan and banks with no default reject the plan. Our definition of an equilibrium is therefore analogous: an equilibrium is a pair of strategies $\left(\sigma_{n}\right.$, $\sigma_{s}$ ) chosen by banks with medium default in the nonsevere and severe crises, respectively, with $\sigma \in\{\operatorname{Re}, A\}$. In contrast to the one-bank model, however, the incentive compatibility conditions associated with a given strategy are not identical across states of the world. This is due to the fact that Bank 2's expected performance enters into the reputation terms for Bank 1, and Bank 2's expected performance is a function of the state of the world. Thus, Bank 1's optimal strategy is indirectly a function of the state of the world, and two incentive compatibility conditions must be satisfied for each equilibrium to exist.

For purposes of illustration we consider the equilibrium $(\operatorname{Re}, \operatorname{Re})$. In this equilibrium banks with default in the nonsevere crisis reject the plan, as do banks with default in the severe crisis. Suppose that the crisis is nonsevere. The only bank with default in this state of the world is the low type. If this bank rejects the plan, its expected utility is

$$
\begin{gathered}
U_{n}^{L}(\operatorname{Re})=\widehat{B}-L-E c+ \\
{[p+(1-p) \theta]\left\{a p^{1+}\left(\operatorname{Re} \mid(\operatorname{Re}, \operatorname{Re}), \pi^{2+}(\operatorname{Re})\right)+(1-a) p^{1 m}\left(\operatorname{Re} \mid(\operatorname{Re}, \operatorname{Re}), \pi^{2+}(\operatorname{Re})\right)\right\}} \\
+(1-p)(1-\theta)\left\{a \mid a p^{1+}\left(\operatorname{Re} \mid(\operatorname{Re}, \operatorname{Re}), \pi^{2+}(\operatorname{Re})\right)+(1-a) p^{1+}\left(\operatorname{Re} \mid(\operatorname{Re}, \operatorname{Re}), \pi^{2 m}(\operatorname{Re})\right)\right] \\
\left.+(1-a)\left[a p^{1 m}\left(\operatorname{Re} \mid(\operatorname{Re}, \operatorname{Re}), \pi^{2+}(\operatorname{Re})\right)+(1-a) p^{1 m}\left(\operatorname{Re} \mid(\operatorname{Re}, \operatorname{Re}), \pi^{2 m}(\operatorname{Re})\right)\right]\right\}
\end{gathered}
$$

\footnotetext{
${ }^{20}$ Proofs of our results for the assumptions used in Section 3 are available upon request.
} 
where $p^{1+}\left(\operatorname{Re} \mid(\operatorname{Re}, \operatorname{Re}), \pi^{2+}(\operatorname{Re})\right)$ represents Bank 1's updated reputation when it rejects the plan and reports high current net worth, given that the market expects banks' strategies to be $(\operatorname{Re}, \operatorname{Re})$ and given that Bank 2 also rejects the plan and has high current net worth. The term $p^{1 m}\left(\operatorname{Re} \mid(\operatorname{Re}, \operatorname{Re}), \pi^{2+}(\operatorname{Re})\right)$ represents Bank 1's updated reputation when it rejects the plan and rollover fails, given that Bank 2 has rejected the plan and reported high current net worth. Bank 1 does not know Bank 2's type. With probability $[p+(1-p) \theta]$ Bank 2 will have no default and will reject the plan and report high current net worth. With probability $(1-p)(1-\theta)$ Bank 2 will have default, in which case it will reject the plan and report high current net worth with probability $a$ and medium current net worth with probability $(1-a)$. Expressions for the reputation terms appear in the appendix.

If Bank 1 deviates from the expected strategies and accepts the plan, its expected utility is given by

$$
\begin{gathered}
U_{n}^{L}(A)=(\widehat{B}-L+R)+[p+(1-p) \theta]\left[p^{1 m}\left(A \mid(\operatorname{Re}, \operatorname{Re}), \pi^{2+}(\operatorname{Re})\right)\right] \\
+(1-p)(1-\theta)\left\{a p^{1 m}\left(A \mid(\operatorname{Re}, \operatorname{Re}), \pi^{2+}(\operatorname{Re})\right)+(1-a) p^{1 m}\left(A \mid(\operatorname{Re}, \operatorname{Re}), \pi^{2 m}(\operatorname{Re})\right)\right\}
\end{gathered}
$$

where $p^{1 m}\left(A \mid(\operatorname{Re}, \operatorname{Re}), \pi^{2+}(\operatorname{Re})\right)$ represents Bank 1's updated reputation given that it accepts the plan and given that Bank 2 rejects the plan and reports high current net worth. Note that each of the reputation terms in the above expression is off the equilibrium path; therefore, we have to make assumptions about out-of-equilibrium beliefs. We make an assumption similar to that of Section 3. For the term $p^{1 m}\left(A \mid(\operatorname{Re}, \operatorname{Re}), \pi^{2+}(\operatorname{Re})\right)$ we assume that the market computes the probability that Bank 1 is a high type, given that it accepts the plan and given that Bank 2 rejects the plan and reports high current net worth. It is easily verified that $p^{1 m}\left(A \mid(\operatorname{Re}, \operatorname{Re}), \pi^{2+}(\operatorname{Re})\right)=p^{1 m}\left(\operatorname{Re} \mid(\operatorname{Re}, \operatorname{Re}), \pi^{2+}(\operatorname{Re})\right)$. Similarly, $p^{1 m}\left(\operatorname{Re} \mid(\operatorname{Re}, \operatorname{Re}), \pi^{2 m}(\operatorname{Re})\right)=p^{1 m}\left(A \mid(\operatorname{Re}, \operatorname{Re}), \pi^{2 m}(\operatorname{Re})\right)$.

Using these observations, we may write the low type bank's IC constraint in the nonsevere crisis as

$$
\begin{aligned}
E c+R \leq & {[p+(1-p) \theta] a\left\{p^{1+}\left(\operatorname{Re} \mid(\operatorname{Re}, \operatorname{Re}), \pi^{2+}(\operatorname{Re})\right)-p^{1 m}\left(\operatorname{Re} \mid(\operatorname{Re}, \operatorname{Re}), \pi^{2+}(\operatorname{Re})\right\}\right.} \\
& {[(1-p)(1-\theta)] a\left\{\left[a p^{1+}\left(\operatorname{Re} \mid(\operatorname{Re}, \operatorname{Re}), \pi^{2+}(\operatorname{Re})\right)+(1-a) p^{1+}\left(\operatorname{Re} \mid(\operatorname{Re}, \operatorname{Re}), \pi^{2 m}(\operatorname{Re})\right)\right]\right.} \\
& \left.-\left[a p^{1 m}\left(\operatorname{Re} \mid(\operatorname{Re}, \operatorname{Re}), \pi^{2+}(\operatorname{Re})\right)+(1-a) p^{1 m}\left(\operatorname{Re} \mid(\operatorname{Re}, \operatorname{Re}), \pi^{2 m}(\operatorname{Re})\right)\right]\right\} .
\end{aligned}
$$

Now suppose that the crisis is severe. When the high-type bank rejects the plan, its 
expected utility is

$$
\begin{gathered}
U_{s}^{H}(\operatorname{Re})=\widehat{B}-E c-L \\
+p\left\{a\left[a p^{1+}\left(\operatorname{Re} \mid(\operatorname{Re}, \operatorname{Re}), \pi^{2+}(\operatorname{Re})\right)+(1-a) p^{1+}\left(\operatorname{Re} \mid(\operatorname{Re}, \operatorname{Re}), \pi^{2 m}(\operatorname{Re})\right)\right]\right. \\
\left.+(1-a)\left[a p^{1 m}\left(\operatorname{Re} \mid(\operatorname{Re}, \operatorname{Re}), \pi^{2+}(\operatorname{Re})\right)+(1-a) p^{1 m}\left(\operatorname{Re} \mid(\operatorname{Re}, \operatorname{Re}), \pi^{2 m}(\operatorname{Re})\right)\right]\right\} \\
+(1-p)\left(1-a c_{p}\right)
\end{gathered}
$$

With probability $p$ Bank 2 will have a medium level of default and will reject the plan. In this case with probability $a$ Bank 2 will succeed in reporting high current net worth. With probability $(1-p)$ Bank 2 will be a low type and has a high level of default. In this case Bank 2 will accept the plan, in which case the market knows that the crisis is severe and that Bank 1 is a high type. The regulator, however, now knows that Bank 1 rolled over its defaulting loans. Therefore, even in the case where Bank 1 succeeded with rollover and was able to report a high current net worth, the regulator can impose the cost $c_{p}$ on the bank. This explains the appearance of the term $-(1-p) a c_{p}$ in addition to the inclusion of $(1-a) c_{p}$ in the definition of $E c$.

When the bank accepts the plan, its expected utility is

$$
\begin{gathered}
U_{s}^{H}(A)=R+\widehat{B}-L \\
+p\left\{a p^{1 m}\left(A \mid(\operatorname{Re}, \operatorname{Re}), \pi^{2+}(\operatorname{Re})\right)+(1-a) p^{1 m}\left(A \mid(\operatorname{Re}, A), \pi^{2 m}(\operatorname{Re})\right)\right\}+(1-p) \cdot 1
\end{gathered}
$$

The incentive compatibility constraint for the high type in the severe crisis can be expressed, after some rearrangement, as

$$
\begin{aligned}
E c+R \leq & p a\left\{a \mid p^{1+}\left(\operatorname{Re} \mid(\operatorname{Re}, \operatorname{Re}), \pi^{2+}(\operatorname{Re})\right)-p^{1 m}\left(\operatorname{Re} \mid(\operatorname{Re}, \operatorname{Re}), \pi^{2+}(\operatorname{Re})\right)\right] \\
& \left.+(1-a)\left[p^{1+}\left(\operatorname{Re} \mid(\operatorname{Re}, \operatorname{Re}), \pi^{2 m}(\operatorname{Re})\right)-p^{1 m}\left(\operatorname{Re} \mid(\operatorname{Re}, \operatorname{Re}), \pi^{2 m}(\operatorname{Re})\right)\right]\right\} \\
& -(1-p) a c_{p} .
\end{aligned}
$$

A necessary condition for the equilibrium $(\mathrm{Re}, \mathrm{Re})$ to exist is that the right-hand side of each incentive compatibility constraint is positive. It turns out that with our assumptions on default in this section, there exist parameter values for which this necessary condition is not satisfied; i.e., for which the RHS of at least one of the IC constraints is negative. This results from the fact that for certain combinations of parameter values (namely, $\pi$ and $\theta$ ) 
a bank's reputation is actually lower when it rejects the plan and reports high current net worth than when it accepts the plan or than when it rejects the plan and reports medium current net worth. In this case the RHS of the constraint becomes negative.

That the bank's reputation may be higher when it reveals default than when it rejects the plan and reports high current net worth may appear counterintuitive; however, the explanation is logical. In the severe crisis all banks have default, but only the high type has a medium level of default. Therefore, if the market's prior $\pi$ on the severe crisis is high enough (and if the value of $\theta$ is "large enough" so that low types have medium default with only low probability in the nonsevere crisis), then revelation of a medium level of default signals good news about the bank's type. In this situation, high type banks have an incentive to accept the plan in the severe crisis. However, the low-type bank with default in the nonsevere crisis may now also have an incentive to accept the plan.

Note that with the assumptions on default used in the model of Section 3, this situation does not arise; the RHS of the each of the above IC constraints is always positive. The explanation follows from the fact that as $\theta$ increases, the low-type bank has a larger probability of having a medium level of default in the severe crisis, which offsets the corresponding decrease in the probability of the low type having medium default in a nonsevere crisis. A medium level of default no longer signals good news about the bank's type.

A higher reputation associated with revelation versus nonrevelation of default by hightype banks in severe crises is consistent with the practice sometimes observed whereby the healthier banks are the first to reveal and write off bad loans during a crisis, and they improve their reputations by doing so. ${ }^{21}$ In our model, a lowering of the probability that the low type has a medium level of default in the severe crisis relative to its probability of having no default in the nonsevere crisis has the effect of improving the high type's ability to signal its type by revealing its default when it has loan defaults. As a consequence, the region of the parameter space for which banks will accept the plan increases.

\footnotetext{
${ }^{21}$ See Gibson (1999) for a model in which the same result occurs. Good banks can use loan-loss disclosures to signal information about their quality to markets. Gibson also supplies empirical evidence of this phenomenon for the U.S. and Japan.
} 


\subsection{Characterization of equilibria in the two-bank model.}

We first describe pure-strategy equilibria $(\operatorname{Re}, \operatorname{Re})$ and $(A, A)$. Discussion of these equilibria applies to parameter values for which the equilibrim (Re, Re) may exist; i.e., for which the RHS of the both incentive compatibility constraints in the ( $\mathrm{Re}, \mathrm{Re})$ equilibrium are positive.

Proposition 4 There exist critical values $c^{R R}(a)$ and $c^{A A}(a)$, with $c^{A A}(a)>c^{R R}(a)$, such that an equilibrium $(\mathrm{Re}, \mathrm{Re})$ exists if $c^{R R}(a)>0$ and $E c+R \leq c^{R R}(a)$; and an equilibrium $(A, A)$ exists if $E c+R \geq c^{A A}(a)$.

Proof: See appendix.

The description of equilibria $(\operatorname{Re}, \operatorname{Re})$ and $(A, A)$ is similar to that for the one-bank model, with the principal difference being that in the two-bank model the critical value $c^{R R}(a)$ is the minimum of the critical values implied by each of the incentive compatibility conditions for the equilibrium ( $\mathrm{Re}, \mathrm{Re})$; and the critical value $c^{A A}(a)$ is the maximum of the critical values implied by each of the incentive compatibility conditions for the equilibrium $(A, A)$.

We now turn to the possibility of equilibria where the strategies differ in each state of the world. The following proposition demonstrates that the only pure-strategy equilibrium in which banks with default in the nonsevere crisis will adopt a different strategy from banks in the severe crisis is the equilibrium $(\operatorname{Re}, A)$. In this equilibrium banks with default reject the plan when the crisis is nonsevere; however, they accept the plan when the crisis is severe. This implies that regulators will not be able to successfully rescue banks unless the crisis is severe.

Proposition 5 (i) There exists a critical value $c^{R A}(a)$ such that an equilibrium $(\operatorname{Re}, A)$ exists if $c^{R A}(a)>0$ and $E c+R \leq c^{R A}(a)$; (ii) the equilibrium $(A, \operatorname{Re})$ does not exist.

Proof: See appendix.

The intuition associated with the equilibrium $(\operatorname{Re}, A)$ is that given the market's beliefs, a high-type bank in the severe crisis can signal its type by accepting the plan, since it knows that Bank 2 will accept the plan and the market will believe that the crisis is severe. On the other hand, if Bank 1 rejects the plan when Bank 2 accepts, the market is not sure of the state of the world, and Bank 1 loses its ability to signal its type. The incentive 
compatibility constraint for acceptance of the plan by the high type in the severe crisis is thus always satisfied. In contrast, the bank with default in the nonsevere crisis cannot perfectly fool the market by accepting the plan, since Bank 2 will always reject the plan in the nonsevere crisis. Hence, if $E c+R$ is low enough, the bank with default in the nonsevere crisis has the incentive to reject the plan.

What can we say about the occurrence of the equilibrium ( $\mathrm{Re}, \mathrm{Re}$ ) versus the equilibrium $(\operatorname{Re}, A)$ ? In the equilibrium $(\mathrm{Re}, \mathrm{Re})$ the incentive constraint for the high type is more binding than the IC constraint for the low type. A necessary and sufficient condition for existence of this equilibrium is that $E c+R \leq$ RHS (4). In addition, the IC constraint for the high type in the equilibrium ( $R e, R e)$ requires a lower value of $E c+R$ than the IC constraint for the low type in the equilibrium ( Re, $A$ ). Thus, $c^{R R}<c^{R A}$. The equilibrium (Re, $A$ ) exists for a larger range of parameter values than does the equilibrium $(\operatorname{Re}, \operatorname{Re})$. For all values of $E c+R$ for which the equilibrium $(\operatorname{Re}, \operatorname{Re})$ exists, the equilibrium $(\operatorname{Re}, A)$ also exists.

Proposition 5 shows that it impossible in equilibrium for banks with default in the severe crisis to reject a plan if banks in the nonsevere crisis accept the plan. This result arises again from the fact that it is always easier to induce a bank with medium default in the severe crisis to accept a plan than a bank with medium default in the nonsevere crisis. Hence, if the sum $E c+R$ is high enough to induce banks to accept the plan in the nonsevere crisis, then this sum will be too large to be compatible with rejection of the plan by the high-type bank in the severe crisis.

In summary, the interaction of banks' strategies in this model motivates banks to accept plans more readily in a severe crisis than in a nonsevere crisis. This leads to the possibility of equilibria where, although banks with default reject the plan in the nonsevere crisis, banks with default in the severe crisis will accept the plan. Regulators who wish to offer bank rescues may not be successful in doing so until the banking crisis is severe.

\section{The optimal rescue plan}

The analysis of the previous sections has taken the conditions of rescue plans-that is, the values of $R$ and $c_{p}$-as given. On the basis of this analysis we may make some tentative 
observations regarding the conditions of rescue plans that would be chosen by the regulator when she takes into account the effects of reputation on banks' willingness to accept rescue plans. In this section we discuss aspects of the regulator's choice of rescue plan, without undertaking a comprehensive analysis of this choice.

We take as given that regulators who have decided to offer banks rescue plans perceive some expected benefit $V$ from the rescue of a troubled bank. One might expect that the value of $V$ increases with the regulator's belief $\pi$ that the banking crisis is severe and as the negative externalities associated with multiple bank failures increase. Consider a regulatory objective function with the following simple form:

$$
\max \left\{\left[V I_{A}-g(R)\right], 0\right\}
$$

where $V$ is the expected benefit associated with the rescue of a troubled bank; $I_{A}$ is an indicator function which takes on a value of 1 if the bank accepts the rescue offer and 0 otherwise; $g(R)$ is the cost function associated with recapitalization. We assume that $g(\cdot)$ is nondecreasing in the amount of recapitalisation $R$ offered to the bank. Note that the indicator function $I$ is a function of all of the parameters identified in Sections 3 and 4 that influence banks' willingness to accept rescue plans: the state of the world, the amount of recapitalization offered in the plan, the expected costs of rollover $c_{b}$ and $c_{p}$, and the reputation formed in the market.

The regulator's problem is to choose $c_{p}$ and $R$, subject to constraints on the maximum feasible values of these variables, to maximize the above objective function. The maximum feasible value of $c_{p}$, which we will denote by $\bar{c}_{p}$, is determined by the financial system and existing regulatory institutions. The regulator may also face a constraint $\bar{R}$ on $R$, if the amount of recapitalization that can be offered is subject to a budgetary limit.

For simplicity we consider the regulator's choice in the context of the one-bank model. We then note how the results would differ in the two-bank model. A first result follows immediately.

Proposition 6 The regulator will choose $c_{p}=\bar{c}_{p}$ in any rescue plan.

The analysis of Sections 3 and 4 has identified the unambiguously positive effect of the cost $c_{p}$ on banks' willingness to accept rescue plans. Moreover, imposing the cost $c_{p}$ in a 
rescue plan has no effect on the regulator's cost function; therefore, the regulator chooses the maximum level. This result leads to some additional observations. If $\bar{c}_{p}$ is sufficiently high to induce the bank to accept the plan with certainty (i.e., to induce the ( $A, A$ ) equilibrium), then the regulator will offer a rescue plan with only negligible recapitalization. If, on the other hand, $\bar{c}_{p}$ is sufficiently low that the bank will reject a plan with no recapitalization, then the regulator must consider offering a positive level of $R$.

Now consider the level of recapitalization $R^{A}(a)=c^{A}(a)-E c$, defined in Section 3.2 as the minimum level of recapitalization required to induce the bank to accept a rescue plan with certainty. Denote by $R^{A}\left(a, \bar{c}_{p}\right)$ this minimum level of recapitalization when $c_{p}=\bar{c}_{p}$. We take $R^{A}\left(a, \bar{c}_{p}\right)$ to be equal to 0 if $\bar{c}_{p}$ is sufficiently high to induce the bank to accept a plan with no recapitalization. We now define another level of recapitalization: $R^{r e}\left(a, \bar{c}_{p}\right)=c^{r e}(a)-E c$, where $c^{r e}(a)$ is defined in Section 3.1 and where we use $\bar{c}_{p}$ in the definition of $E c . R^{r e}\left(a, \bar{c}_{p}\right)$ represents the maximum amount of recapitalization such that the equilibrium $(\operatorname{Re}, \operatorname{Re})$ exists. That is, if $R^{r e}\left(a, \bar{c}_{p}\right)>0$, then any rescue plan with $R<$ $R^{r e}\left(a, \bar{c}_{p}\right)$ will be rejected with certainty. We may now state a second, immediate result.

Proposition 7 Let $R^{*}$ be the optimal amount of recapitalization offered in a rescue plan. Then, $R^{r e}\left(a, \bar{c}_{p}\right) \leq R^{*} \leq R^{A}\left(a, \bar{c}_{p}\right)$, with $R^{*}=R^{A}\left(a, \bar{c}_{p}\right)$ when the regulator wishes for the bank to accept the plan with certainty.

This proposition states that the regulator never offers a rescue plan with an amount of recapitalization less than $\max \left[R^{r e}\left(a, \bar{c}_{p}\right), 0\right]$, since this rescue plan would be rejected with certainty. This also implies that if the regulator faces a constraint on the amount of recapitalization that she can offer and if $\bar{R}<R^{r e}\left(a, \bar{c}_{p}\right)$, then no rescue plan will be offered. The proposition also implies that the regulator never offers a rescue plan with a level of capitalization that exceeds $R^{A}\left(a, \bar{c}_{p}\right)$, since a plan with $R^{A}\left(a, \bar{c}_{p}\right)$ will be accepted with certainty. If the regulator chooses to offer a rescue plan that induces the equilibrium $(A, A)$, then she will offer exactly $R^{A}\left(a, \bar{c}_{p}\right)$. Recall that this level of recapitalization may be zero if $\bar{c}_{p}$ is sufficiently high.

There may nevertheless exist circumstances in which the regulator chooses a level of recapitalization that is strictly less than $R^{A}\left(a, \bar{c}_{p}\right)$. Recall from Section 3.3 that for values of $E c+R$ such that $c^{\operatorname{Re}}(a)<E c+R<c^{A}(a)$, no pure strategy equilibria exist; equilibria are in mixed strategies. For each value of $E c+R$ in this range, there is some positive 
probability that the bank will accept the plan (otherwise, an equilibrium in pure strategies would exist). Consider a value $\widehat{R}$ such that $c^{\operatorname{Re}}(a)<E c+\widehat{R}<c^{A}(a)$. Assume that the probability that the bank accepts the plan in the mixed-strategy equilibrium induced by $\widehat{R}$ is equal to $\lambda$. The regulator's expected utility from offering a rescue plan with $\bar{c}_{p}$ and $\widehat{R}$ is given by

$$
\lambda[V-g(\widehat{R})]
$$

With probability $\lambda$ the bank accepts the plan and the regulator's utility will equal $V-g(\widehat{R})$; with probability $(1-\lambda)$ the bank will reject the plan and the regulator's utility will equal zero. In order to decide whether to offer the rescue plan with $\widehat{R}$ rather than $R^{A}\left(a, \bar{c}_{p}\right)$, the regulator must compare $\lambda[V-g(\widehat{R})]$ with $V-g\left(R^{A}\left(a, \bar{c}_{p}\right)\right)$. If the costs of offering $R^{A}\left(a, \bar{c}_{p}\right)$ in recapitalization are high enough or if the probability $\lambda$ is high enough, the regulator's utility will be higher with the rescue plan with $\widehat{R}$. In this case the regulator will choose to offer the lower amount of recapitalization $\widehat{R}$, knowing that with some probability the bank will reject the plan. The optimal level of recapitalization will be the value $R^{*}$ in the range $R^{r e}\left(\bar{c}_{p}\right) \leq R^{*} \leq R^{A}\left(a, \bar{c}_{p}\right)$ which maximizes the regulator's expected utility.

Now consider the model with two banks. The results of the above discussion also apply to this model, with the additional result that there exist levels of recapitalization that generate the pure-strategy equilibrium $(\operatorname{Re}, A)$ in which banks will reject the plan if the crisis is nonsevere and accept the plan if the crisis is severe. Similarly to the case of mixedstrategy equilibria discussed above, it can be shown that the optimal level of recapitalization offered in the rescue plan may be one that generates the equilibrium $(\operatorname{Re}, A)$. In this case, only if the crisis is severe will banks be willing to accept the plan.

In summary, when the regulator takes into account banks' reputational concerns, the optimal rescue plan will involve imposition of the maximum feasible value of $c_{p}$ on banks that reject rescue plans then report loan defaults. In addition, the level of recapitalization offered in the optimal rescue plan may be low enough so that with positive probability the plan will be rejected. Banks' reputational concerns can result in the equilibrium rejection of optimal rescue plans. 


\section{Conclusion}

This paper models bank behavior during banking crises when asymmetric information exists between banks and outsiders regarding the extent of bad loans on banks' balance sheets. We show that asymmetric information creates the incentive for banks to roll over their nonperforming loans in an attempt to disguise their financial states. Although a regulator may be able to combat this incentive by offering a "soft" rescue package, reputational concerns by bankers may cause them to reject rescue offers and to continue with loan rollovers. In order to induce banks to accept rescue plans and to address their problem loans, regulators may be forced to offer amounts of recapitalization that well exceed the amount necessary to restore banks to solvency. This "extra" recapitalization serves to compensate bankers for the reputational harm caused by the revelation of bad loans that accompanies acceptance of a rescue offer. If regulators are constrained in the amount of recapitalization that they can offer, they may be unable to induce banks to accept rescue plans and to reveal their bad loans, or they may have to wait until the banking crisis is severe (and more banks become distressed) before banks are willing to accept rescues.

In addition to offering a potential explanation for several observed cases in which banks have refused offers of rescue in banking crises, our model yields some insight into the link between bank supervisory institutions that are in place $e x$ ante and the policy options that are available to regulators ex post, once a crisis has occurred. In countries with strong supervisory systems, regulators can induce banks to accept rescue plans with lower amounts of recapitalization than if the supervisory system were weak. This suggests the possibility of a vicious circle arising in countries with weak supervisory institutions, whereby weak banking supervision increases the probability of occurrence of a banking crisis, but once a banking crisis develops banks are unwilling to reveal their bad loans unless offered a large amount of recapitalisation.

A novel policy implication of our analysis is that the optimal rescue plan imposes a cost on banks that reject rescue offers and then exhibit poor performance. By committing to imposing a punishment on banks which reject rescue offers and then are discovered to be in poor financial shape, the regulator can induce troubled banks to accept a rescue offer with less recapitalization than in the absence of such a commitment. If this cost is high enough, the regulator can induce banks to accept rescue plans with only negligible recapitalization. 
This result points to an informational role that is served by bank rescue offers in our model. An offer of rescue forces a bank to take an explicit stand with respect to the presence of bad loans on its balance sheets. The bank's acceptance or rejection of a rescue offer conveys information to bank outsiders-which they would not otherwise receive-about the severity of the banking crisis, the bank's type, and its treatment of nonperforming loans. This creates the possibility of punishing banks who attempt to hide their nonperforming loans and are discovered. The ultimate effect of the increase in information generated by the offer of a rescue plan is to induce banks to reveal their defaulting loans more often than in the absence of rescue offers.

Yet, banks may still decide to reject rescue offers. Even when the regulator takes into account bankers' reputational concerns in designing a rescue offer, rejection of the rescue offer may occur in equilibrium. For example, it is possible that high costs of recapitalization may result in an optimal plan in which the regulator offers an amount of recapitalization which will be accepted by banks only if the crisis is severe enough. If the crisis is less severe, banks will reject the offer.

To this point our discussion and analysis have ignored depositor behavior. We can now address this issue. Like the market, depositors do not observe the state of the world or the bank's type. When a bank rejects a rescue plan in period 1 and succeeds, depositors are unaware of the bank's true financial state. However, one might reasonably assume that depositors do observe the true financial state of the bank in period 2. Therefore, even if a bank with loan defaults has succeeded in hiding the defaults in period 1, depositors will observe the bank's true net worth in period 2 and can decide to exit the bank. This would impose an additional cost on the bank which rolled over its defaulting loans in period 1 , and this cost could easily be added into the parameter $c_{b}$ of our model. Thus, the more sensitive are depositors to the bank's solvency, the greater the costs to banks of rolling over nonperforming loans.

Similar observations apply to the parameter $c_{p}$ in our model. We have described this parameter as a cost imposed by the regulator on troubled banks that have rejected rescue plans and then are discovered by the regulator. In this case depositors, too, immediately discover not only the bank's defaulting loans but also the fact that the bank attempted to deceive outsiders by hiding these loans. Depositors may react to this deception by 
immediately withdrawing their funds, which could act as an increase to $c_{p}$. This increase would have the effect of increasing banks' willingness to accept rescue plans. Thus, in countries where discipline exercised by depositors is strong enough, banks may be willing to accept rescue plans with only small amounts of recapitalization. Discipline exercised by depositors complements the discipline exercised by the regulatory system. 


\section{A Appendix}

\section{A.1 One-bank model}

\section{A.1.1 Proof of Lemma 1:}

Only low-type banks have a high level of default. If the bank with high default accepts the plan, its expected utility will be

$$
U(A)=(1-\gamma)(R-L)+\gamma p^{\circ}(A)
$$

Since acceptance of the plan and revelation of a high level of default signal the bank's type with certainty, the market assigns a value of 0 to the reputation term $p^{\circ}(A)$, which is the conditional probability that the bank is a high type. The bank's expected utility in the case where it rejects the plan will be

$$
U(\operatorname{Re})=-(1-\gamma)\left(L+c_{b}+c_{p}\right)+\gamma p^{o}(\operatorname{Re})
$$

where we note that $p^{\circ}(\mathrm{Re})$ is also zero since this bank never succeeds with rollover. Since $U(A)>U(\operatorname{Re})$, the low-type bank will always choose to accept the plan when it has a high level of default. $\|$

\section{A.1.2 Reputation terms for equilibrium (Re,Re)}

$$
p^{+}(\operatorname{Re} \mid(\operatorname{Re}, \operatorname{Re}), \pi)=\frac{p[(1-\pi)+\pi a]}{p[(1-\pi)+\pi a]+(1-p)(1-\pi)[\theta+(1-\theta) a]+(1-p) \pi \theta a}
$$

and

$$
\begin{gathered}
p^{m}(\operatorname{Re} \mid(\operatorname{Re}, \operatorname{Re}), \pi)=\frac{p \pi(1-a)}{p \pi(1-a)+(1-p)(1-a)[(1-\pi)(1-\theta)+\pi \theta]} \\
=\frac{p \pi}{p \pi+(1-p)[(1-\pi)(1-\theta)+\pi \theta]}
\end{gathered}
$$

\section{A.1.3 Reputation terms for equilibrium (A,A)}

$$
\begin{gathered}
p^{+}(\operatorname{Re} \mid(A, A), 0)=\frac{p}{p+(1-p) \theta} \\
p^{m}(A \mid(A, A), \pi)=\frac{p \pi}{p \pi+(1-p)[(1-\pi)(1-\theta)+\pi \theta]}
\end{gathered}
$$




\section{A.1.4 Proof of Proposition 1:}

Part (i) of the proposition summarizes the discussion of the subsections 3.1 and 3.2. Part (ii) of the proposition follows from two observations: (1) $E c=c_{b}+(1-a) c_{p}$ is decreasing in $a$; and $(2) c^{\operatorname{Re}}(a)$ and $c^{A}(a)$ are increasing in $a$. Thus, for given values $c_{b}$ and $R$, as $a$ increases, $E c+R$ decreases and $c^{\mathrm{Re}}(a)$ and $c^{A}(a)$ increase. This implies that the region of values of $E c+R$ over which an equilibrium (Re, Re) exists increases with increasing $a$ and the region of $E c+R$ over which an equilibrium $(A, A)$ exists decreases with $a$. $\|$

\section{A.1.5 Proof of Proposition 2:}

(i) Conditions for an equilibrium $(\operatorname{Re}, A)$ :

In this equilibrium the market assumes that the crisis is nonsevere ( $\operatorname{sets} \pi=0$ in updating the bank's reputation) when the bank rejects a plan. Similarly, the market assumes that the crisis in severe when the bank accepts a plan.

Two IC conditions must be satisfied in order for this equilibrium to exist.

Nonsevere crisis:

$U(\operatorname{Re} \mid(\operatorname{Re}, A))=(1-\gamma)(\widehat{B}-L-E c)+\gamma\left\{a p^{+}(\operatorname{Re} \mid(\operatorname{Re}, A), 0)+(1-a)\left[p^{m}(\operatorname{Re} \mid(\operatorname{Re}, A), 0)\right]\right\}$,

where the last argument of $p^{+}(\operatorname{Re} \mid(\operatorname{Re}, A), 0)$ indicates that the market infers that the state of the world is $n$ when the bank rejects the rescue plan.

$$
p^{+}(\operatorname{Re} \mid(\operatorname{Re}, A), 0)=\frac{p}{p+(1-p)[\theta+(1-\theta) a]}
$$

and

$$
p^{m}(\operatorname{Re} \mid(\operatorname{Re}, A), 0)=0 .
$$

The bank's utility if it accepts the plan is

$$
U(A \mid(\operatorname{Re}, A))=(1-\gamma)(R+\widehat{B}-L)+\gamma p^{m}(A \mid(\operatorname{Re}, A), 1) .
$$

When the bank accepts the plan, the market assumes that the state is $s$; therefore, it sets $\pi=1$ when updating the bank's repuation.

$$
p^{m}(A \mid(\operatorname{Re}, A), 1)=\frac{p}{p+(1-p) \theta}
$$


The IC constraint for state $n$ is

$$
E c+R \leq \frac{\gamma}{(1-\gamma)}\left[a p^{+}(\operatorname{Re} \mid(\operatorname{Re}, A), 0)-p^{m}(A \mid(\operatorname{Re}, A), 1)\right]
$$

That $p^{+}(\operatorname{Re} \mid(\operatorname{Re}, A), 0) \leq p^{m}(A \mid(\operatorname{Re}, A), 1)$ implies that the RHS of this constraint is negative, and the constraint cannot be satisfied. Hence, the equilibrium $(\operatorname{Re}, A)$ does not exist.

(ii) Conditions for an equilibrium with $(A, \mathrm{Re})$ :

Nonsevere crisis:

The bank's expected utility from accepting the plan is

$$
U(A \mid(A, \operatorname{Re}))=(1-\gamma)(R+\widehat{B}-L)+\gamma\left[p^{m}(A \mid(A, \operatorname{Re}), 0)\right]
$$

When the bank accepts the plan, the market believes that the state is $n$, in which case $p^{m}(A \mid(A, \operatorname{Re}), 0)=0$.

The bank's expected utility from rejecting the plan is

$U(\operatorname{Re} \mid(A, \operatorname{Re}))=(1-\gamma)(\widehat{B}-L-E c)+\gamma\left[a p^{+}(\operatorname{Re} \mid(A, \operatorname{Re}), \pi)+(1-a) p^{m}(\operatorname{Re} \mid(A, \operatorname{Re}), 1)\right]$

When the bank rejects the plan then has high current net worth, the market cannot tell whether the state is $n$ and the bank has no default or whether the state is $s$. The market's prior $\pi$ on the state remains unchanged.

$$
p^{+}(\operatorname{Re} \mid(A, \operatorname{Re}), \pi)=\frac{p[(1-\pi)+\pi a]}{p[(1-\pi)+\pi a]+(1-p)[(1-\pi) \theta+\pi \theta a]}=\frac{p}{p+(1-p) \theta}
$$

When the bank rejects the plan then reports low current net worth, the market believes that the state is $s$. In this case

$$
p^{m}(\operatorname{Re} \mid(A, \operatorname{Re}), 1)=\frac{p}{p+(1-p) \theta}
$$

The IC condition is 


$$
R+E c \geq \frac{\gamma}{(1-\gamma)}\left[a p^{+}(\operatorname{Re} \mid(A, \operatorname{Re}), \pi)+(1-a) p^{m}(\operatorname{Re} \mid(A, \operatorname{Re}), 1)\right]
$$

or

$$
R+E c \geq \frac{\gamma}{(1-\gamma)}\left[\frac{p}{p+(1-p) \theta}\right]
$$

Severe crisis:

The bank's expected utilities are as follows:

$U(\operatorname{Re} \mid(A, \operatorname{Re}))=(1-\gamma)(\widehat{B}-L-E c)+\gamma\left[a p^{+}(\operatorname{Re} \mid(A, \operatorname{Re}), \pi)+(1-a) p^{m}(\operatorname{Re} \mid(A, \operatorname{Re}), 1)\right]$

$$
U(A \mid(A, \operatorname{Re}))=(1-\gamma)(R+\widehat{B}-L)+\gamma\left[p^{m}(A \mid(A, \operatorname{Re}), 0)\right]
$$

The IC condition is

$$
E c+R \leq \frac{\gamma}{(1-\gamma)}\left[\frac{p}{p+(1-p) \theta}\right]
$$

Comparison of the two IC constraints implies that each must be satisfied with equality in order for the equilibrium to exist. $\|$

\section{A.2 Two-bank model}

\section{A.2.1 Reputation terms for equilibrium (Re,Re)}

$$
\begin{gathered}
p^{1+}\left(\operatorname{Re} \mid(\operatorname{Re}, \operatorname{Re}), \pi^{2+}(\operatorname{Re})\right)=\frac{p(1-\pi)[p+(1-p)(\theta+(1-\theta) a)]+p \pi p a^{2}}{(1-\pi)[p+(1-p)(\theta+(1-\theta) a)]^{2}+p \pi p a^{2}}, \\
p^{1 m}\left(\operatorname{Re} \mid(\operatorname{Re}, \operatorname{Re}), \pi^{2+}(\operatorname{Re})\right)=\frac{p \pi p a}{p \pi p a+(1-p)(1-\pi)(1-\theta)[p+(1-p)(\theta+(1-\theta) a)]}
\end{gathered}
$$




$$
\begin{gathered}
p^{1+}\left(\operatorname{Re} \mid(\operatorname{Re}, \operatorname{Re}), \pi^{2 m}(\operatorname{Re})\right)=\frac{p(1-\pi)[(1-p)(1-\theta)]+p \pi p a}{[p+(1-p)(\theta+(1-\theta) a)](1-\pi)[(1-p)(1-\theta)]+p \pi p a} \\
p^{1 m}\left(\operatorname{Re} \mid(\operatorname{Re}, \operatorname{Re}), \pi^{2 m}(\operatorname{Re})\right)=\frac{p \pi p}{p \pi p+(1-p)^{2}(1-\pi)(1-\theta)^{2}}
\end{gathered}
$$

\section{A.2.2 Proof of Proposition 4:}

Equilibrium (Re, $\operatorname{Re})$ :

The IC constraints are provided in the text.

Define $c^{1 r e}=$ RHS of IC constraint (3).

Define $c^{2 r e}=$ RHS of IC constraint (4). Define $c^{R R}(a)=\min \left[c^{1 r e}, c^{2 r e}\right]$. Then necessary and sufficient conditions for existence of this equilibrium are: $(1) c^{R R}(a)>0$ and $(2)$ $E c+R \leq c^{R R}(a)$.

Equilibrium $(A, A)$ :

Nonsevere crisis; low type

$$
\begin{aligned}
U_{n}^{L}(A)= & R+\widehat{B}-L+[p+(1-p) \theta] p^{1 m}\left(A \mid(A, A), \pi^{2+}(\operatorname{Re})\right) \\
& +(1-p)(1-\theta) p^{1 m}\left(A \mid(A, A), \pi^{2 m}(A)\right) .
\end{aligned}
$$

When Bank 2 rejects the plan and has high current earnings, the market knows that the state is $n$; therefore, $p^{1 m}\left(A \mid(A, A), \pi^{2+}(\mathrm{Re})\right)=0$.

$$
\begin{gathered}
p^{1 m}\left(A \mid(A, A), \pi^{2 m}(A)\right)=\frac{p \pi p}{p \pi p+(1-p)^{2}(1-\pi)(1-\theta)^{2}} \\
U_{n}^{L}(\operatorname{Re})=\widehat{B}-E c-L \\
+[p+(1-p) \theta]\left[a p^{1+}\left(\operatorname{Re} \mid(A, A), \pi^{2+}(\operatorname{Re})\right)+(1-a) p^{1 m}\left(\operatorname{Re} \mid(A, A), \pi^{2+}(\operatorname{Re})\right)\right] \\
+(1-p)(1-\theta)\left[a p^{1+}\left(\operatorname{Re} \mid(A, A), \pi^{2 m}(A)\right)+(1-a) p^{1 m}\left(\operatorname{Re} \mid(A, A), \pi^{2 m}(A)\right)\right.
\end{gathered}
$$

Note that $p^{1 m}\left(\operatorname{Re} \mid(A, A), \pi^{2+}(\operatorname{Re})\right)=0$ for the same reason that $p^{1 m}\left(A \mid(A, A), \pi^{2+}(\operatorname{Re})\right)=$ 0. 
The low type's incentive compatibility constraint is

$$
\begin{gathered}
E c+R \geq[p+(1-p) \theta] a p^{1+}\left(\operatorname{Re} \mid(A, A), \pi^{2+}(\operatorname{Re})\right) \\
+(1-p)(1-\theta) a\left[p^{1+}\left(\operatorname{Re} \mid(A, A), \pi^{2 m}(A)\right)-p^{1 m}\left(\operatorname{Re} \mid(A, A), \pi^{2 m}(A)\right)\right]
\end{gathered}
$$

Note that

$$
p^{1+}\left(\operatorname{Re} \mid(A, A), \pi^{2+}(\operatorname{Re})\right)=p^{1+}\left(\operatorname{Re} \mid(A, A), \pi^{2 m}(A)\right)=\frac{p}{p+(1-p) \theta}
$$

since the market knows that the state is $n$ when it observes a bank reject a plan. We may rewrite the IC constraint as

$$
\left.E c+R \geq a p^{1+}\left(\operatorname{Re} \mid(A, A), \pi^{2+}(\operatorname{Re})\right)-(1-p)(1-\theta) a p^{1 m}\left(\operatorname{Re} \mid(A, A), \pi^{2 m}(A)\right)\right]
$$

Severe crisis; high type

$$
\begin{aligned}
& U_{s}^{H}(A)=R+\widehat{B}+p\left[p^{1 m}\left(A \mid(A, A), \pi^{2 m}(A)\right)+(1-p) \cdot 1\right. \\
& U_{s}^{H}(\operatorname{Re})= \widehat{B}-E c-L+p\left[a p^{1+}\left(\operatorname{Re} \mid(A, A), \pi^{2 m}(A)\right)+(1-a) p^{1 m}\left(\operatorname{Re} \mid(A, A), \pi^{2 m}(A)\right)\right] \\
&+(1-p)\left(1-a c_{p}\right)
\end{aligned}
$$

The high type's IC constraint is

$$
E c+R \geq p\left[a p^{1+}\left(\operatorname{Re} \mid(A, A), \pi^{2 m}(A)\right)+(1-a) p^{1 m}\left(\operatorname{Re} \mid(A, A), \pi^{2 m}(A)\right)\right]-(1-p) a c_{p}
$$

Define $c^{1 A}(a)=$ RHS of IC constraint (8). Define $c^{2 A}(a)=$ RHS of IC constraint (9). Define $c^{A A}(a)=\max \left[c^{1 A}(a), c^{2 A}(a)\right]$. A necessary and sufficient condition for the existence of the equilibrium $(A, A)$ is that $E c+R \geq c^{A A}(a)$.

\section{A.2.3 Proof of Proposition 5:}

Part (i): Equilibrium (Re,A)

Severe crisis; high-type bank 
Consider Bank 1 and suppose that it is a high type. This bank's expected utility when it accepts the plan is given by

$$
U_{s}^{H}(A)=R+\widehat{B}-L+p\left\{p^{1 m}\left(A \mid(\operatorname{Re}, A), \pi^{2 m}(A)\right)\right\}+(1-p) p^{1 m}\left(A \mid(\operatorname{Re}, A), \pi^{2 o}(A)\right) .
$$

With probability $p$ Bank 2 is a high type and accepts the plan, in which case $p^{1 m}(A \mid$ $\left.(\operatorname{Re}, A), \pi^{2 m}(A)\right)$ will be Bank 1's updated reputation. Given that acceptance of a plan by both banks signals to the market that the crisis is severe (since banks with default reject the plan in a nonsevere crisis), the market knows that Bank 1 is a high type. Hence, $p^{1 m}\left(A \mid(\operatorname{Re}, A), \pi^{2 m}(A)\right)=1$. With probability $(1-p)$ Bank 2 is a low type and will accept the plan and report a high level of default. In this case, too, the market will know that Bank 1 is a high type and will also assign a value of 1 to Bank 1's updated reputation. Thus, we may reexpress Bank 1's expected utility when it accepts the plan as

$$
U_{s}^{H}(A)=R+\widehat{B}-L+1
$$

Bank 1's expected utility if it rejects the plan is given by

$$
\begin{aligned}
U_{s}^{H}(\operatorname{Re})= & \widehat{B}-L-E c+p\left[a p^{1+}\left(\operatorname{Re} \mid(\operatorname{Re}, A), \pi^{2 m}(A)\right)+(1-a) p^{1 m}\left(\operatorname{Re} \mid(\operatorname{Re}, A), \pi^{2 m}(A)\right)\right] \\
& +(1-p)\left(1-a c_{p}\right)
\end{aligned}
$$

Neither of the reputation terms $p^{1+}\left(\operatorname{Re} \mid(\operatorname{Re}, A), \pi^{2 m}(A)\right)$ or $p^{1 m}\left(\operatorname{Re} \mid(\operatorname{Re}, A), \pi^{2 m}(A)\right)$ can be calculated via Bayes' rule. We follow the method discussed earlier in assigning expressions for these terms. $p^{1+}\left(\operatorname{Re} \mid(\operatorname{Re}, A), \pi^{2 m}(A)\right)$ is calculated as the probability that Bank 1 is a high type given that it rejects the plan and has high current net worth and given that Bank 2 accepts the plan and has medium current net worth.

$$
\begin{gathered}
p^{1+}\left(\operatorname{Re} \mid(\operatorname{Re}, A), \pi^{2 m}(A)\right)= \\
\frac{p[\pi p a+(1-\pi)(1-p)(1-\theta)]}{p[\pi p a+(1-\pi)(1-p)(1-\theta)]+(1-p)(1-\pi)[\theta+(1-\theta) a][(1-p)(1-\theta)]}
\end{gathered}
$$

Also,

$$
p^{1 m}\left(\operatorname{Re} \mid(\operatorname{Re}, A), \pi^{2 m}(A)\right)=\frac{p \pi p}{p \pi p+(1-p)^{2}(1-\pi)(1-\theta)^{2}} .
$$

The high type's incentive compatibility constraint is

$$
\begin{aligned}
E c+R \geq & p\left\{a p^{1+}\left(\operatorname{Re} \mid(\operatorname{Re}, A), \pi^{2 m}(A)\right)+(1-a) p^{1 m}\left(\operatorname{Re} \mid(\operatorname{Re}, A), \pi^{2 m}(A)\right)\right\} \\
& -p-(1-p) a c_{p} .
\end{aligned}
$$


The expression inside the brackets in the RHS of 11 is less than 1 ; therefore, $p\{\cdot\}$ is less than $p$. The RHS of 11 is negative, and this incentive compatibility constraint is always satisfied.

\section{Nonsevere crisis; low-type bank}

Suppose that Bank 1 is a low type and has default. If it rejects the plan, its expected utility will be given by

$$
\begin{gathered}
U_{n}^{L}(\operatorname{Re})=\widehat{B}-L-E c+ \\
{[p+(1-p) \theta]\left\{a p^{1+}\left(\operatorname{Re} \mid(\operatorname{Re}, A), \pi^{2+}(\operatorname{Re})\right)+(1-a) p^{1 m}\left(\operatorname{Re} \mid(\operatorname{Re}, A), \pi^{2+}(\operatorname{Re})\right\}\right.} \\
+(1-p)(1-\theta)\left\{a \mid a p^{1+}\left(\operatorname{Re} \mid(\operatorname{Re}, A), \pi^{2+}(\operatorname{Re})\right)+(1-a) p^{1+}\left(\operatorname{Re} \mid(\operatorname{Re}, A), \pi^{2 m}(\operatorname{Re})\right)\right] \\
\left.+(1-a)\left[a p^{1 m}\left(\operatorname{Re} \mid(\operatorname{Re}, A), \pi^{2+}(\operatorname{Re})\right)+(1-a) p^{1 m}\left(\operatorname{Re} \mid(\operatorname{Re}, A), \pi^{2 m}(\operatorname{Re})\right)\right]\right\} .
\end{gathered}
$$

When the market observes both banks reject the plan, it assumes that the state is $n$; thus, when Bank 1 rejects the plan and rollover fails, the market knows that the bank is a low type and assigns a value of zero to $p^{1 m}\left(\operatorname{Re} \mid(\operatorname{Re}, A), \pi^{2+}(\operatorname{Re})\right)$ and to $p^{1 m}\left(\operatorname{Re} \mid(\operatorname{Re}, A), \pi^{2 m}(\operatorname{Re})\right)$. In addition,

$$
p^{1+}\left(\operatorname{Re} \mid(\operatorname{Re}, A), \pi^{2+}(\operatorname{Re})\right)=p^{1+}\left(\operatorname{Re} \mid(\operatorname{Re}, A), \pi^{2 m}(\operatorname{Re})\right)=\frac{p}{p+(1-p)[\theta+(1-\theta) a]} .
$$

Using these observations we may rewrite the low type's expected utility when it rejects the plan as

$$
U_{n}^{L}(\operatorname{Re})=\widehat{B}-L-E c+a p^{1+}\left(\operatorname{Re} \mid(\operatorname{Re}, A), \pi^{2+}(\operatorname{Re})\right)
$$

If Bank 1 accepts the plan, its expected utility is

$$
\begin{gathered}
U_{n}^{L}(A)=\widehat{B}+R-L+[p+(1-p) \theta]\left[p^{1 m}\left(A \mid(\operatorname{Re}, A), \pi^{2+}(\operatorname{Re})\right)\right] \\
+(1-p)(1-\theta)\left\{a p^{1 m}\left(A \mid(\operatorname{Re}, A), \pi^{2+}(\operatorname{Re})\right)+(1-a) p^{1 m}\left(A \mid(\operatorname{Re}, A), \pi^{2 m}(\operatorname{Re})\right)\right\} .
\end{gathered}
$$

We note that $p^{1 m}\left(A \mid(\operatorname{Re}, A), \pi^{2+}(\operatorname{Re})\right)$ and $p^{1 m}\left(A \mid(\operatorname{Re}, A), \pi^{2 m}(\operatorname{Re})\right)$ cannot be computed by Bayes' rule. We follow the procedure described earlier for computing these values.

$$
p^{1 m}\left(A \mid(\operatorname{Re}, A), \pi^{2+}(\operatorname{Re})\right)=\frac{p^{2} \pi a}{p^{2} \pi a+(1-p)(1-\pi)(1-\theta)[p+(1-p)[\theta+(1-\theta) a]]}
$$




$$
p^{1 m}\left(A \mid(\operatorname{Re}, A), \pi^{2 m}(\operatorname{Re})\right)=\frac{p^{2} \pi}{p^{2} \pi+(1-p)^{2}(1-\pi)(1-\theta)^{2}} .
$$

The low type's IC constraint is

$$
\begin{gathered}
E c+R \leq \\
{[p+(1-p) \theta]\left\{a p^{1+}\left(\operatorname{Re} \mid(\operatorname{Re}, A), \pi^{2+}(\operatorname{Re})\right)-p^{1 m}\left(A \mid(\operatorname{Re}, A), \pi^{2+}(\operatorname{Re})\right)\right\}} \\
+[(1-p)(1-\theta)]\left\{a\left[p^{1+}\left(\operatorname{Re} \mid(\operatorname{Re}, A), \pi^{2+}(\operatorname{Re})\right)-p^{1 m}\left(A \mid(\operatorname{Re}, A), \pi^{2+}(\operatorname{Re})\right)\right]\right. \\
\left.\left.-(1-a) p^{1 m}\left(A \mid(\operatorname{Re}, A), \pi^{2 m}(\operatorname{Re})\right)\right]\right\} .
\end{gathered}
$$

A necessary condition for this constraint to be satisfied is that the RHS is positive. It can be shown that the RHS is positive for values of $\pi$ and $\theta$ "low enough" and for values of $a$ high enough. therefore, the IC constraint will be satisfied for values of $a$ high enough and for values of $E c+R$ low enough. Thus, sufficient conditions for the equilibrium $(\operatorname{Re}, A)$ to exist are that $a$ be high enough and that $E c+R$ be less than the RHS of constraint 12 . An example of parameter values for which the RHS is positive is $p=.6 \pi_{o}=.5 \theta=.3 a=.9$.

\section{Part (ii) Equilibrium ( $A, \operatorname{Re}$ )}

Nonsevere crisis; low-type bank

When the low type accepts the plan, its expected utility is

$$
\begin{aligned}
U_{n}^{L}(A)= & R+\widehat{B}+(p+(1-p) \theta) p^{1 m}\left(A \mid(A, \operatorname{Re}), \pi^{2+}(\operatorname{Re})\right) \\
& +(1-p)(1-\theta) p^{1 m}\left(A \mid(A, \operatorname{Re}), \pi^{2 m}(A)\right),
\end{aligned}
$$

where both of the reputation terms equal zero. Acceptance of the plan signals to the market that the crisis is severe, in which case only the low type can have default. We may thus rewrite the expected utility as

$$
U_{n}^{L}(A)=R+\widehat{B}
$$

When the low type rejects the plan, its expected utility is

$$
\begin{gathered}
U_{n}^{L}(\operatorname{Re})=\widehat{B}-E c+ \\
{[p+(1-p) \theta]\left\{a p^{1+}\left(\operatorname{Re} \mid(A, \operatorname{Re}), \pi^{2+}(\operatorname{Re})\right)+(1-a) p^{1 m}\left(\operatorname{Re} \mid(A, \operatorname{Re}), \pi^{2+}(\operatorname{Re})\right)\right\}} \\
+[(1-p)(1-\theta)]\left\{a p^{1+}\left(\operatorname{Re} \mid(A, \operatorname{Re}), \pi^{2 m}(A)\right)+(1-a) p^{1 m}\left(\operatorname{Re} \mid(A, \operatorname{Re}), \pi^{2 m}(A)\right)\right\}
\end{gathered}
$$


where

$$
p^{1+}\left(\operatorname{Re} \mid(A, \operatorname{Re}), \pi^{2+}(\operatorname{Re})\right)=\frac{p\left(1-\pi_{o}\right)[p+(1-p) \theta]+p^{2} \pi_{o} a^{2}}{\left(1-\pi_{o}\right)[p+(1-p) \theta]^{2}+p^{2} \pi_{o} a^{2}} .
$$

When the market observes that both banks reject the plan and one bank has a medium level of default, the market assumes that the crisis is severe; therefore, $p^{1 m}\left(\operatorname{Re} \mid(A, \operatorname{Re}), \pi^{2+}(\operatorname{Re})\right)=$ 1. When the market observes one bank reject the plan and report high current net worth and the other bank accept the plan, it assumes that the crisis is nonsevere. Thus,

$$
p^{1+}\left(\operatorname{Re} \mid(A, \operatorname{Re}), \pi^{2 m}(A)\right)=\frac{p}{p+(1-p) \theta} .
$$

We must define the out-of-equilibrium belief for the term $p^{1 m}\left(\operatorname{Re} \mid(A, \operatorname{Re}), \pi^{2 m}(A)\right)$.We follow the procedure described above.

$$
p^{1 m}\left(\operatorname{Re} \mid(A, \operatorname{Re}), \pi^{2 m}(A)\right)=\frac{p \pi p}{p \pi p+(1-p)^{2}(1-\pi)(1-\theta)^{2}}
$$

The IC constraint for the low type is

$$
\begin{gathered}
E c+R \geq[p+(1-p) \theta]\left\{a p^{1+}\left(\operatorname{Re} \mid(A, \operatorname{Re}), \pi^{2+}(\operatorname{Re})\right)+(1-a)\right\} \\
+[(1-p)(1-\theta)]\left\{a p^{1+}\left(\operatorname{Re} \mid(A, \operatorname{Re}), \pi^{2 m}(A)\right)+(1-a) p^{1 m}\left(\operatorname{Re} \mid(A, \operatorname{Re}), \pi^{2 m}(A)\right)\right\}
\end{gathered}
$$

\section{Severe crisis; high type}

When the high type rejects the plan, its expected utility is

$$
\begin{gathered}
U_{s}^{H}(\operatorname{Re})=\widehat{B}-E c \\
+p\left\{a\left[a p^{1+}\left(\operatorname{Re} \mid(A, \operatorname{Re}), \pi^{2+}(\operatorname{Re})\right)+(1-a) p^{1+}\left(\operatorname{Re} \mid(A, \operatorname{Re}), \pi^{2 m}(\operatorname{Re})\right)\right]\right. \\
\left.+(1-a)\left[a p^{1 m}\left(\operatorname{Re} \mid(A, \operatorname{Re}), \pi^{2+}(\operatorname{Re})\right)+(1-a) p^{1 m}\left(\operatorname{Re} \mid(A, \operatorname{Re}), \pi^{2 m}(\operatorname{Re})\right)\right]\right\} \\
+(1-p)\left(1-a c_{p}\right) .
\end{gathered}
$$

We note that $p^{1+}\left(\operatorname{Re} \mid(A, \operatorname{Re}), \pi^{2 m}(\operatorname{Re})\right)=1$. In addition,

$$
p^{1 m}\left(\operatorname{Re} \mid(A, \operatorname{Re}), \pi^{2+}(\operatorname{Re})\right)=p^{1 m}\left(\operatorname{Re} \mid(A, \operatorname{Re}), \pi^{2 m}(\operatorname{Re})\right)=1 .
$$


We may thus rewrite the expected utility given that the high type rejects the plan as

$$
\begin{gathered}
U_{s}^{H}(\operatorname{Re})=\widehat{B}-E c \\
+p\left\{a\left[a p^{1+}\left(\operatorname{Re} \mid(A, \operatorname{Re}), \pi^{2+}(\operatorname{Re})\right)+(1-a)\right]+(1-a)\right\}+(1-p)\left(1-a c_{p}\right)
\end{gathered}
$$

When the high type accepts the plan, its expected utility is

$$
\begin{gathered}
U_{s}^{H}(A)=\widehat{B}-E c+p\left[a p^{1 m}\left(A \mid(A, \operatorname{Re}), \pi^{2+}(\operatorname{Re})\right)+(1-a) p^{1 m}\left(A \mid(A, \operatorname{Re}), \pi^{2 m}(\operatorname{Re})\right)\right] \\
+(1-p) 1
\end{gathered}
$$

where $p^{1 m}\left(A \mid(A, \operatorname{Re}), \pi^{2+}(\operatorname{Re})\right)=0$, and where $p^{1 m}\left(A \mid(A, \operatorname{Re}), \pi^{2 m}(\operatorname{Re})\right)$ is calculated in a similar manner to the reputation term $p^{1 m}\left(\operatorname{Re} \mid(A, \operatorname{Re}), \pi^{2 m}(A)\right)$ above. (It is easily verified that these two terms are equal.) Using these observations, we may rewrite the high type's expected utility as

$$
U_{s}^{H}(A)=\widehat{B}-E c+p(1-a) p^{1 m}\left(A \mid(A, \operatorname{Re}), \pi^{2 m}(\operatorname{Re})\right)+(1-p)
$$

The IC constraint for the high type is

$$
\begin{gathered}
E c+R \leq p\left\{a^{2} p^{1+}\left(\operatorname{Re} \mid(A, \operatorname{Re}), \pi^{2+}(\operatorname{Re})\right)+a(1-a)+(1-a)\right\} \\
-p(1-a) p^{1 m}\left(A \mid(A, \operatorname{Re}), \pi^{2 m}(\operatorname{Re})\right)-(1-p) a c_{p} .
\end{gathered}
$$

In order to show that the equilibrium $(A, \mathrm{Re})$ does not exist, it suffices to demonstrate that the RHS of IC constraint (13) is greater than the RHS of IC constraint (14); hence, that the two IC constraints are inconsistent.

Lemma 2 The IC constraint (14) is inconsistent with the IC constraint (13).

Proof: Observe that $p^{1+}\left(\operatorname{Re} \mid(A, \operatorname{Re}), \pi^{2+}(\operatorname{Re})\right)>p$ and $p^{1+}\left(\operatorname{Re} \mid(A, \operatorname{Re}), \pi^{2 m}(A)\right)>p$. Using this observation, we can identify a necessary condition for constraint (13) to be satisfied:

$$
\begin{gathered}
E c+R \geq[p+(1-p) \theta+(1-p)(1-\theta)] a p+ \\
(1-a)\left\{p+(1-p) \theta+(1-p)(1-\theta) p^{1 m}\left(\operatorname{Re} \mid(A, \operatorname{Re}), \pi^{2 m}(A)\right)\right\}
\end{gathered}
$$


$E c+R \geq a p+(1-a) p+(1-a)(1-p) \theta+(1-a)(1-p)(1-\theta) p^{1 m}\left(\operatorname{Re} \mid(A, \operatorname{Re}), \pi^{2 m}(A)\right)$

A necessary condition for the IC constraint (14) to be satisfied is that

$$
\begin{aligned}
E c+R & \leq a p\left\{a p^{1+}\left(\operatorname{Re} \mid(A, \operatorname{Re}), \pi^{2+}(\operatorname{Re})\right)+(1-a)\right\}+p(1-a) \\
& \leq a p+p(1-a) .
\end{aligned}
$$

Conditions (15) and (16) are inconsistent since the RHS of (15) is greater than the RHS of (16). Hence, the IC constraints (14) and (13) cannot simultaneously be satisfied. I 


\section{References}

[1] Aghion, Philippe, Bolton, Patrick, and Fries, Stephen. "Optimal Design of Bank Bailouts: The Case of Transition Economics," EBRD Working Paper 32, 1998.

[2] Athukorala, P, 1999. "The Malaysian Experiment", conference paper from Reform and Recovery in East Asia: The Role of the State and Economic Enterprise, Canberra: ANU.

[3] Benston, G. and G. Kaufman. "FDICIA After Five Years: A Review and Evaluation," Journ. Econ. Perspectives, Vol. 11, 1997: 139-159.

[4] Boot, Arnoud W. and Thakor, Anjan. "Self-Interested Bank Regulation," Amer. Econ. Rev., Vol. 83, No. 2(May, 1993):206-212.

[5] Corbett, J. "Japan's Banking Crisis in International Perspective," in M. Aoki and G. Saxonhouse (eds.). Finance, Governance, and Competitiveness in Japan. Oxford: Oxford Univ. Press, 1999.

[6] Dewatripont, Mathias and Tirole, Jean. The Prudential Regulation of Banks, МП Press, 1994.

[7] Dreyfus, J.-F., A. Saunders, and L. Allen. "Deposit Insurance and Regulatory Forebearance: Are Caps on Insured Deposits Optimal?," Journ. Mon., Cred., Bank, Vol. 26 (1994): 412-438.

[8] Gibson, Scott. "On the Information Content of Bank Loan-Loss Disclosures: A Theory and Evidence from Japan," International Review of Finance, 1999.

[9] Krueger, A and A Tornell, 1999. " The Role of Bank Restructuring in Recovering from Crises: Mexico 1995-98" NBER Working Paper 7042.

[10] Lindgren C-J, et al. , 1996, Bank Soundness and Macroeconomic Policy, Washington: IMF.

[11] Mailath, George and Mester, Loretta. "When Do Regulators Close Banks: When Should They?" Journ. Fin. Intermed., 1993. 
[12] McQuerry, M, 1999. "The Banking Sector Rescues in Mexico" Federal Reserve Bank of Atlanta Economic Review, Vol 84, No 3: 14 - 29.

[13] Mitchell, Janet. “The Problem of Bad Debts: Cleaning Banks' Balance Sheets in Economies in Transition," CEPR Discussion Paper No 1977, London, 1998b.

[14] Mitchell, Janet. "Strategic Creditor Passivity, Regulation, and Bank Bailouts," CEPR Discussion Paper No. 1780, London, 1998a.

[15] O'Hara, Maureen. "Real Bills Revisited: Market Value Accounting and Loan Maturity," Journ. Finan. Intermed., 1993.

[16] Rajan, Raghuram. "Why Bank Credit Policies Fluctuate: A Theory and Some Evidence," Quart. Journ. Econ., Vol. 109, No. 2 (May, 1994):399-442.

[17] Rochet, J.-C. and Tirole, Jean. "Interbank Lending and Systemic Risk," Journ. Mon., Cred., Bank., Vol. 28:733-762.

[18] Roulier, Richard. "Governance Issues and Banking System Soundness," in Charles Enoch and John H. Green, eds. Banking Soundness and Monetary Policy, Washington: IMF, 1997.

[19] Smith, H, 1999, "The State, Banking and Corporate Relationships: Korea and Taiwan" conference paper from Reform and Recovery in East Asia: The Role of the State and Economic Enterprise, Canberra: ANU. 